\title{
Zintl Phases as Reactive Precursors for Synthesis of Novel Silicon and Germanium-Based Materials
}

\author{
Matt Beekman ${ }^{1, *(\mathbb{D})}$, Susan M. Kauzlarich $\left.{ }^{2} \mathbb{(}\right)$, Luke Doherty ${ }^{1,3}$ and George S. Nolas ${ }^{4}$ \\ 1 Department of Physics, California Polytechnic State University, San Luis Obispo, CA 93407, USA; \\ ladohert@calpoly.edu \\ 2 Department of Chemistry, University of California, Davis, CA 95616, USA; smkauzlarich@ucdavis.edu \\ 3 Department of Materials Engineering, California Polytechnic State University, San Luis Obispo, CA 93407, USA \\ 4 Department of Physics, University of South Florida, Tampa, FL 33620, USA; gnolas@usf.edu \\ * Correspondence: mbeekman@calpoly.edu
}

Received: 5 February 2019; Accepted: 27 March 2019; Published: 8 April 2019

\begin{abstract}
Recent experimental and theoretical work has demonstrated significant potential to tune the properties of silicon and germanium by adjusting the mesostructure, nanostructure, and/or crystalline structure of these group 14 elements. Despite the promise to achieve enhanced functionality with these already technologically important elements, a significant challenge lies in the identification of effective synthetic approaches that can access metastable silicon and germanium-based extended solids with a particular crystal structure or specific nano/meso-structured features. In this context, the class of intermetallic compounds known as Zintl phases has provided a platform for discovery of novel silicon and germanium-based materials. This review highlights some of the ways in which silicon and germanium-based Zintl phases have been utilized as precursors in innovative approaches to synthesize new crystalline modifications, nanoparticles, nanosheets, and mesostructured and nanoporous extended solids with properties that can be very different from the ground states of the elements.
\end{abstract}

Keywords: silicon; germanium; Zintl phase; metastable; allotropes; soft chemistry; nanoparticles; mesostructured materials

\section{Introduction}

For nearly 100 years, the elements silicon and germanium have received much attention from chemists, physicists, and materials scientists due in large part to their immense technological importance in semiconductor and optoelectronic applications as well as their richness in chemical properties [1-3]. Although current technologies are dominated by the well-studied (and relatively well understood) diamond structured forms known as $\alpha$-Si and $\alpha$-Ge, there also exist more "exotic" forms of these elements [4], including alternative crystalline modifications [5-9], amorphous states [10], and various nanostructured forms [11,12] that can have remarkably different properties. Early indications of the promise for tuning properties in these elements through structural modification were revealed by studies of porous silicon [13] and expanded low-density crystalline silicon allotropes [14], both of which show increased electronic band gaps relative to $\alpha$-Si. Porous silicon provides a striking example of the influence of size/nanostructure on properties (through the mechanism of quantum confinement [15]), whereas silicon clathrate allotropes demonstrate the importance of atomic arrangement on the electronic structure of a crystal. Since such attributes can be used independently or in combination to obtain materials with new and possibly improved functionality, novel silicon and germanium-based materials comprise more than mere scientific curiosities.

More recently, advanced computational approaches and revived theoretical interest in elemental modifications have established that the possible phase space for new forms of silicon and germanium is 
much richer than originally thought [16-20]. For example, hundreds of relatively low-energy crystalline modifications of silicon have been theoretically predicted, many of which could have promising light absorption properties, which are of interest for improved photovoltaics $[17,18]$. The expanded frameworks found in clathrate modifications possess interesting thermal properties, such as tunable thermal expansion [21] and low thermal conductivity [22], and could find application as anodes in lithium ion batteries [23,24]. The growing ability to prepare mesostructured and nanostructured silicon and germanium-based materials provides additional mechanisms to target specific material properties [25]. The key challenge limiting progress in all cases, however, is effective synthetic approaches to experimentally obtain a specific material of interest. For example, although hundreds of crystalline elemental modifications of $\mathrm{Si}$ and Ge are conceivable, only a handful of these materials have been prepared in the lab [5]. By definition, all forms other than crystalline $\alpha$-Si and $\alpha$-Ge are thermodynamically metastable under ambient conditions, and such materials are typically difficult to obtain by conventional synthetic approaches.

The use of precursors is particularly attractive for the preparation of metastable and difficult to synthesize solids. Chemical precursors can have structural features that are similar to the desired product, lowering activation energies for transformation and facilitating topotactic reactions. Reducing the need for extensive solid-state diffusion and/or the breaking of strong chemical bonds allows reactions to proceed at lower temperatures. Metastable products can thus be kinetically trapped at local energy minima by halting the reaction at an intermediate step along the path to the most thermodynamically stable products. Different reaction conditions can drive the transformation of the same precursor to different products. In this contribution, we highlight the important role the class of materials known as Zintl phases has assumed in the preparation of new silicon and germanium-based materials. The synthetic approaches discussed below have yielded a variety of new elemental modifications as well as mesostructured solids and nanostructured materials, and hold significant promise for new materials discovery.

\section{Zintl Ions and Zintl Phases}

While there are many design strategies to making new compounds and materials, a very powerful guideline is the Zintl electron counting or Zintl-Klemm concept [26-28]. Zintl phases, sometimes referred to as the valence precise intermetallics, are a large and continually growing collection of compounds whose structure and bonding can be rationalized by simple electron counting rules. A number of excellent reviews and texts covering the structure, chemistry, and properties of Zintl phases are available [26-32], thus we only briefly highlight some important features relevant to their reactivity here.

Named after the pioneering chemist Eduard Zintl [28,29], binary Zintl phases originally garnered fundamental interest both for their interesting structures and their solution reactivity. The structures of Zintl phases typically feature negatively charged subunits that range from isolated $0 \mathrm{D}$ anions or polyatomic clusters to charged 3D networks (Figure 1), such that covalent bonding within the subunits is enabled by transfer of electrons from alkali, alkaline-earth, or rare earth atoms. This charge transfer enables the organization of the constituents in the anionic subunits, which are collectively termed "Zintl ions", in ways that often mimic structures found in the neighboring elements in the periodic table, and the resulting materials are often (but not always) semiconductors prepared from all metallic elements. While representative classical Zintl phases typically contained $p$-block elements, the Zintl concept has since been expanded to transition metal-containing semiconductors, which show unique combinations of properties, such as colossal magnetoresistance and ferromagnetic semiconductors [33,34]. Zintl phases are also receiving significant attention as potential thermoelectric materials [35-37]. 


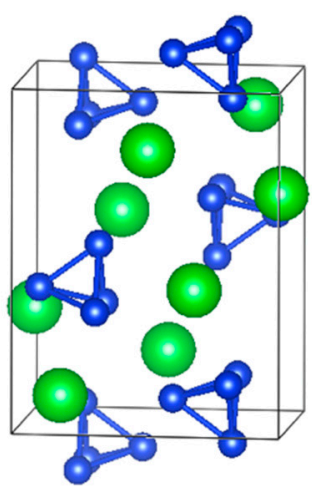

(a) $\mathrm{BaSi}_{2}$

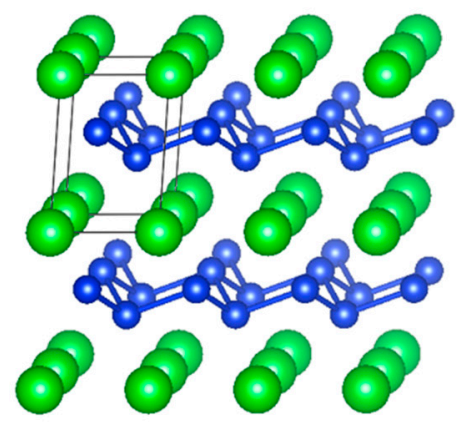

(b) $\mathrm{CaSi}_{2}$

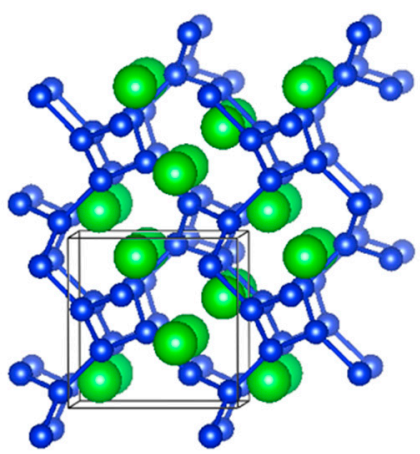

(c) $\mathrm{SrSi}_{2}$

Figure 1. Examples of anionic Zintl subunits found in the crystal structures of three binary $\mathrm{ASi}_{2} \mathrm{Zintl}$ phase $(\mathrm{A}=\mathrm{Ca}, \mathrm{Ba}, \mathrm{Sr})$. (a) $\mathrm{BaSi}_{2}$ contains isolated $\left[\mathrm{Si}_{4}\right]^{4-}$ clusters that are charge balanced by $\mathrm{Ba}^{2+}$ cations. (b) $\mathrm{CaSi}_{2}$ contains $2 \mathrm{D}_{\infty}^{2}\left[\mathrm{Si}_{2}\right]^{2-}$ layers that are charge balanced by $\mathrm{Ca}^{2+}$ cations. (c) $\mathrm{SrSi}_{2}$ contains a $3 \mathrm{D}_{\infty}^{3}\left[\mathrm{Si}_{2}\right]^{2-}$ network that is charge balanced by $\mathrm{Sr}^{2+}$ cations. In all three of these examples of alkaline earth disilicides, each Si atom is 3-bonded to other Si atoms with a formal charge of -1 per $\mathrm{Si}$ atom. (Silicon atoms are shown in blue, alkaline-earth atoms are shown in green.)

There are several features of Zintl phases that lend themselves to use as precursors in materials synthesis. Even from the perspective of traditional high-temperature solid-state reactions, precursors have clear advantages. The elements in a precursor are already homogenously mixed at the atomic level, requiring less solid-state diffusion upon further reaction. The vapor pressure over a compound containing a volatile element, e.g., $\mathrm{Na}$ or $\mathrm{Hg}$, is typically less than that over the element so that reactions employing the compound can be easier to control. However, it is the particular crystal chemistry of Zintl phases that make them amenable to use in low temperature and soft chemical reactions that can yield new materials not accessible by conventional approaches. In many cases, the structural subunits in Zintl phases lend themselves to topotactic reactions in which a metastable intermediate (the target product) has a crystallographic structural relationship to the precursor. Also, upon dissolution of these salt-like solids, the polyatomic Zintl ions found in the crystal are often retained in solution and can be subsequently employed as reactive precursors to new materials $[27,28,38]$. Indeed, Zintl himself studied both the solid-state and the solution chemistry aspect of the compounds that now bear his name [23,38]. It has been demonstrated that oxidative coupling of isolated Zintl clusters can form various 1D polymeric chains [39,40]. The anionic subunits of Zintl phases, including polyanionic clusters (Figure 1a), infinite 2D sheets (Figure 1b), and 3D networks (Figure 1c), essentially comprise covalently bonded structural moieties in the precursor that can act as molecular building blocks from which novel 3D materials can be built or derived via oxidation [41]. Notably, chemical substitutions on various atomic sites in the Zintl ions in the precursor are possible [42,43], enabling a mechanism for adjusting composition and doping of the products derived from them.

\section{Synthesis of Zintl Phases}

The synthesis of most Zintl phases can be achieved via conventional solid-state preparation routes for intermetallic compounds [44]. Many Zintl phases, in particular those that have been used as precursors for synthesis of silicon and germanium-based materials, are thermodynamically stable compounds and can thus be prepared as single phase polycrystalline or single crystalline products by direct reaction of stoichiometric mixtures of the high purity elements in sealed vessels under inert atmosphere. In many cases, both the reactants and the resulting Zintl phases are highly reactive toward moisture and oxygen, thus all handing, including chemical and structural characterization, must be done under a protected environment. Reactions involving alkali metals are typically carried out in welded tantalum or niobium containers, though formation of $\mathrm{Nb}$ or Ta silicides in side reactions can 
occur at higher temperatures [45]. Alternatively, binary Zintl phases can also be prepared in the lab by low temperature reactions with metal hydrides, allowing access to some Zintl phases without the need for niobium or tantalum containers [46]. Binary Zintl phases can also be used as precursors for preparation of ternary or alloyed Zintl phases [47].

\section{Preparation of New Crystalline Elemental Modifications and Frameworks}

It is a rather remarkable fact that a very large number of distinct elemental crystalline structures, perhaps in the tens of thousands, can accommodate Si and Ge atoms in the four-coordinated bonding geometry that these elements prefer, indicating the free energy landscape for these elements is quite complex $[4-9,14,17-20]$. The deviations in bond lengths and angles for many of these structures (relative to the respective $\alpha$-phase) are sufficiently small, thus the corresponding free energy is sufficiently low, and therefore they should be experimentally accessible $[4-9,14,17-20]$. Once formed, the strong covalent interactions in these materials provide sufficient energy barriers to the transformation to the ground state ( $\alpha$-phase) such that the metastable phase can be kinetically trapped. However, despite average bond distances and angles that are often comparable to those found in the $\alpha$-phases, the variation in crystal structure in the different modifications of silicon and germanium results in widely varying electronic and thermal properties [4-9,14,17-22], providing unique opportunities to obtain new materials with improved or distinct functionality. Such materials, if synthesized, could potentially be processed into devices with higher performance using many of the mature processing and fabrication technologies already established for silicon and germanium.

It is well known that metastable modifications of many of the elements can be retained upon decompression from high pressure to ambient conditions [48]. This includes several crystalline allotropes of silicon and germanium $[7,20,49-51]$. While such experiments play a critical role in understanding the chemistry and physics of the elements, the products in these cases are typically limited to those that are thermodynamically stable at high pressure. In addition, low-density allotropes, expected to have interesting and perhaps useful properties [6], cannot be accessed by solely adjusting the temperature and/or pressure of the pure elements. On the other hand, chemical methods have the potential to access a richer variety of metastable materials, and Zintl phases are playing a central role as precursors in such preparation routes. The soft chemistry and/or low temperature reactions involving Zintl precursors discussed in this section are particularly promising for the synthesis of new metastable silicon and germanium-based allotropes and frameworks and, as described in the sections that follow, continue to be developed as such.

\subsection{Chemical Oxidation of Zintl Precursors}

Two of the earliest examples of silicon and germanium allotropes prepared by chemical methods using a Zintl phase precursor were the reports of the so-called allo-Ge and allo-Si phases [52,53]. Von Schnering et al. reported that these novel modifications could be prepared by deintercalation of $\mathrm{Li}$ (and $\mathrm{Na}$ ) from the layered Zintl phases $\mathrm{Li}_{7} \mathrm{Ge}_{12}$ (Figure 2a) and $\mathrm{Li}_{3} \mathrm{NaSi}_{6}$, respectively, via reaction with benzophenone at ambient temperature [52,53], e.g., according to the reaction $\left(\mathrm{Li}_{7} \mathrm{Ge}_{12}+7 \mathrm{Ph}_{2} \mathrm{CO}\right.$ $\rightarrow$ 12allo-Ge $\left.+7 \mathrm{Li}\left(\mathrm{Ph}_{2} \mathrm{CO}\right)\right)$. In the case of allo-Ge, a rough model of the crystal structure was proposed based on interconnection of the Ge layers found in $\mathrm{Li}_{7} \mathrm{Ge}_{12}$ [52]. Potential structural models were subsequently proposed by other workers [54,55], but the structures of allo-Si and allo-Ge were not definitively solved and remained unknown for several decades. The synthesis and characterization of these materials was recently reinvestigated, and more detailed structural characterization was performed [47,56], supporting the conclusion that the formation of allo-Ge proceeds via oxidative coupling of the ${ }_{\infty}^{2}\left[\mathrm{Ge}_{12}\right]^{7-}$ layers that are present in $\mathrm{Li}_{7} \mathrm{Ge}_{12}$. On the other hand, Zeilinger et al. reported that the preparation of allo-Si could not be reproduced with the products from the reaction of $\mathrm{Li}_{15} \mathrm{Si}_{4}$ and $\mathrm{Li}_{3} \mathrm{NaSi}_{6}$ with various protic solvents comprised of mixtures of amorphous $\mathrm{Si}$, nanocrystalline $\alpha$-Si, and clathrate impurities [47]. In both cases, the products of the reactions are microcrystalline powders. 
(a)

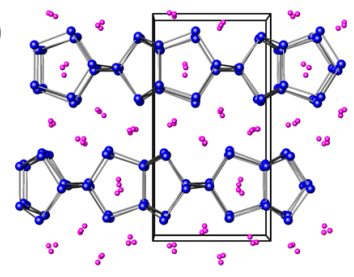

(b)

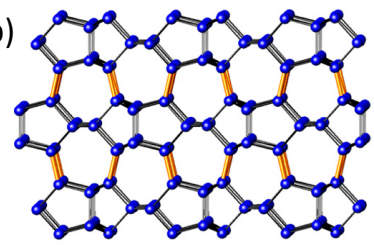

(c)

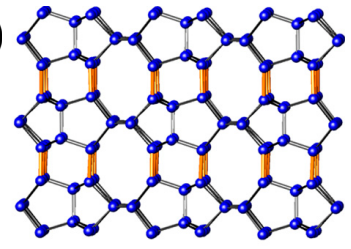

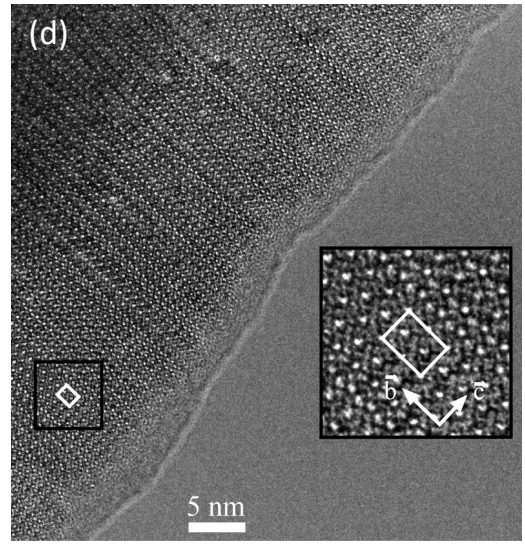

Figure 2. (a) Crystal structure of $\mathrm{Li}_{7} \mathrm{Ge}_{12}$ (Li atoms shown in pink, Ge atoms shown in blue); (b) and (c) show two distinct inter layer couplings that can occur upon oxidation of the ${ }_{\infty}^{2}\left[\mathrm{Ge}_{12}\right]^{7-}$ layers in $\mathrm{Li}_{7} \mathrm{Ge}_{12} ;$ (d) the structure of allo-Ge can be modeled as a statistical mixture of the stackings shown in (b) and (c), evidenced by this high-resolution transmission electron microscope image showing extensive stacking fault disorder along the $\mathrm{c}$ direction; (a) through (c) reproduced with permission from Zaikina, J.V. et al. (Copyright, 2014, American Chemical Society); (d) reproduced with permission from Kiefer, F. et al. (Copyright, 2011, American Chemical Society).

The reinvestigations of the crystal structure of allo-Ge confirm that the five-ring topology present in the ${ }_{\infty}^{2}\left[\mathrm{Ge}_{12}\right]^{7-}$ layers of $\mathrm{Li}_{7} \mathrm{Ge}_{12}$ [57] is retained in allo-Ge [56,58], illustrating the efficacy of topotactic reactions employing Zintl phase precursors by oxidation of lone pair electrons in the layers, and the corresponding formation of additional Ge-Ge interlayer and intralayer bonds to convert the 2D layers into a 3D network. However, good agreement with experimental powder X-ray diffraction data could only be achieved by including stacking disorder in the structural model [56]. The presence of extensive stacking disorder in allo-Ge can be understood in terms of the different energetically feasible ways in which two layers can couple via translations relative to one another during the process of delithiation and oxidation of the anionic layers (see Figure $2 b, c)$. This suggests that the rapidly proceeding reaction produces stacking faults as $\mathrm{Li}$ is removed from the $\mathrm{Li}_{7} \mathrm{Ge}_{12}$ structure [56, 58], supporting the idea that the ${ }_{\infty}^{2}\left[\mathrm{Ge}_{12}\right]^{7-}$ layers in the precursor can couple in various ways [54] depending on the oxidation conditions. When different couplings are possible, such processes can be difficult to control. However, the possibility of coupling the ${ }_{\infty}^{2}\left[\mathrm{Ge}_{12}\right]^{7-}$ layers in $\mathrm{Li}_{7} \mathrm{Ge}_{12}$ in various different stacking sequences also affords the preparation of distinct allotropes from a single precursor. The recently reported $\mathrm{Ge}(\mathrm{oP} 32)$, which can be derived from the structural variants on which the structure of the disordered allo-Ge is based (Figure $2 \mathrm{~b}$ ), was prepared by oxidation of $\mathrm{Li}_{7} \mathrm{Ge}_{12}$ in the ionic liquids dodecyltrimethyl-ammonium aluminum tetrachloride (DTAC) or hexyltrimethylammonium aluminum tetrabromide (HTMAB) at $135-145^{\circ} \mathrm{C}$ for three to seven days [59]. Interestingly, extensive stacking disorder was not reported in this case, indicating different experimental conditions can direct the transformation of the same precursor into different crystalline products.

The oxidation of $\mathrm{Li}_{7} \mathrm{Ge}_{12}$ to form Ge allotropes such as the allo-Ge or $\mathrm{Ge}(o P 32)$ modifications by linking of the ${ }_{\infty}^{2}\left[\mathrm{Ge}_{12}\right]^{7-}$ layers in the precursor provides particularly elegant examples of how the charged 2D structural units afforded in layered Zintl precursors can be used to direct the formation of an elemental allotrope by soft chemical methods. However, other Zintl precursors with isolated cluster anions have also been successfully utilized to prepare new crystalline modifications. A striking example is the preparation of $\mathrm{Ge}(c F 136)$ with the cage-like clathrate-II crystal structure (Figure 3d) [60]. The silicon and germanium frameworks in clathrate structures are built from various face-sharing polyhedra, which usually encapsulate guest atoms inside of the framework cages [61,62]. In contrast, a guest-free $\mathrm{Ge}_{136}$ framework can also be obtained, constituting a new crystalline Ge allotrope $[9,62]$. $\mathrm{Ge}(c F 136)$ can be prepared under various conditions from Na-Ge Zintl precursors such as $\mathrm{Na}_{12} \mathrm{Ge}_{17}$ (Figure 3c). As one example, the reaction of $\mathrm{Na}_{12} \mathrm{Ge}_{17}$ with n-dodecyltrimethylammonium chloride 
(DTAC) in the ionic liquid DTAC $/ \mathrm{AlCl}_{3}$ can be understood as a heterogenous Hofmann-like elimination according to [63]:

$8 \mathrm{Na}_{12} \mathrm{Ge}_{17}+96\left[\mathrm{C}_{12} \mathrm{H}_{25} \mathrm{~N}\left(\mathrm{CH}_{3}\right)_{3}\right] \mathrm{Cl} \rightarrow 24 \mathrm{Ge}_{136}+96 \mathrm{NaCl}+48 \mathrm{H}_{2}+96\left(\mathrm{C}_{10} \mathrm{H}_{21}\right) \mathrm{CH}=\mathrm{CH}_{2}+96 \mathrm{~N}\left(\mathrm{CH}_{3}\right)_{3}$.

(a)

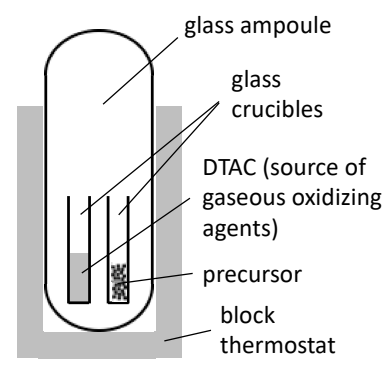

(b)

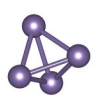

(c)

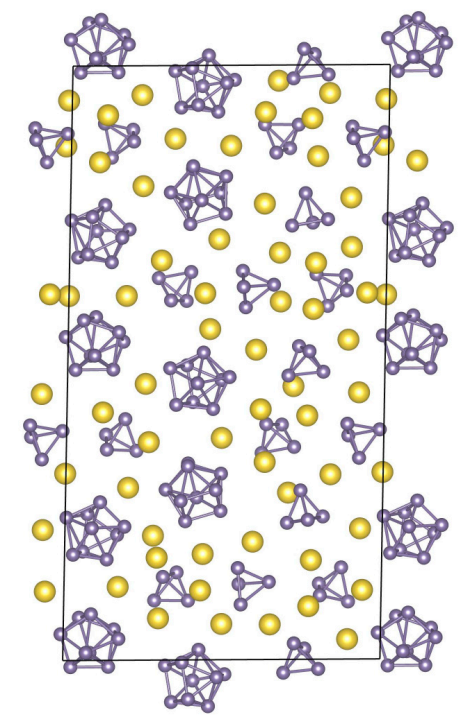

(d)

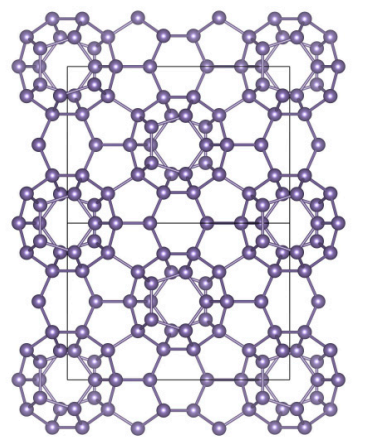

Figure 3. (a) Schematic of the reaction vessel used in the synthesis of Ge(cF136) (adapted from [63]). (b) Isolated $\left[\mathrm{Ge}_{4}\right]^{4-}$ and $\left[\mathrm{Ge}_{9}\right]^{4-}$ Zintl ions found in $\mathrm{Na}_{12} \mathrm{Ge}_{17}$. (c) Partial crystal structure of $\mathrm{Na}_{12} \mathrm{Ge}_{17}$ with $\mathrm{Na}$ atoms shown in yellow [64]. (d) Crystal structure the crystalline Ge modification $\mathrm{Ge}(c F 136)$ that is prepared by mild oxidation of $\mathrm{Na}_{12} \mathrm{Ge}_{17}[60,63]$.

The highly complex crystal structure of $\mathrm{Na}_{12} \mathrm{Ge}_{17}$, shown in Figure $3 c$ [64], contains both $\left[\mathrm{Ge}_{4}\right]^{4-}$ and $\left[\mathrm{Ge}_{9}\right]^{4-}$ Zintl polyanionic clusters that are charge balanced by $\mathrm{Na}^{+}$cations. In contrast to the formation of allo-Ge or $\mathrm{Ge}(o P 32)$, the transformation of polyanionic clusters in $\mathrm{Na}_{12} \mathrm{Ge}_{17}$ into the 3D 4-bonded (4b) network of $\mathrm{Ge}$ atoms in the $\mathrm{Ge}_{136}$ framework requires not only new Ge-Ge bonds to be formed but also existing Ge-Ge bonds to be broken. Presumably, the Na atoms template the formation of the $\mathrm{Ge}_{136}$ framework as the $\left[\mathrm{Ge}_{4}\right]^{4-}$ and $\left[\mathrm{Ge}_{9}\right]^{4-}$ polyanions are oxidized and are then emptied from the clathrate framework cages as the reaction progresses. As with $\mathrm{Li}_{7} \mathrm{Ge}_{12}$, the reaction conditions can have a pronounced effect on the products. For example, spatially separating the precursor from the DTAC significantly improves the yield, reduces the fraction of amorphous by-products, and demonstrates the critical role of gaseous products of DTAC decomposition in the oxidation of the precursor and the heterogeneous nature of the reaction [63]. The generality of mild chemical oxidation of Zintl precursors for preparing silicon and germanium frameworks has now been demonstrated in the synthesis of a wide variety of clathrate phases [60,63,65-69], indicating these synthetic routes deserve continued investigation for the preparation of novel crystalline silicon and germanium modifications.

\subsection{Thermal Decomposition of Zintl Precursors}

Historically, the synthesis of alternative $4 \mathrm{~b}$ silicon and germanium frameworks from Zintl precursors, e.g., the clathrate frameworks (Figure 3c), actually preceded the report of allo-Si by many years. Cros and coworkers showed that the clathrate structures of silicon and germanium $\mathrm{M}_{8} \mathrm{Tt}_{46}$ or $\mathrm{M}_{\mathrm{x}} \mathrm{Tt}_{136}(\mathrm{M}=\mathrm{Na}, \mathrm{K}, \mathrm{Rb}$, or $\mathrm{Cs} ; \mathrm{Tt}=\mathrm{Si}$ or $\mathrm{Ge})$ are obtained upon the thermal decomposition (Figure $4 \mathrm{a}$ ) of alkali metal silicon or germanium Zintl phases $\mathrm{M}_{4} \mathrm{Tt}_{4}$ containing [ $\left.\mathrm{Tt}_{4}\right]^{4-}$ Zintl ions, e.g., Figure $3 \mathrm{~b}[70,71]$. Strictly speaking, these materials are not crystalline allotropes due to the presence of other elements in the structure, namely the guest atoms that occupy the cages formed by the $\mathrm{Si}$ or Ge framework. Nevertheless, the 4-coordinated bonding in these binary $\mathrm{Si}$ and Ge clathrates, 
which is similar to that in the corresponding $\alpha$-phases, alluded to the possibility of obtaining expanded low-density silicon and germanium framework modifications if the guest atoms could be extracted [72]. With rare exceptions [73,74], the alkali metal atoms in clathrate- $\mathrm{I}_{8} \mathrm{Tt}_{46}$ are not easily removed from their polyhedral cages. In contrast, $\mathrm{Na}$ atoms are readily removed from clathrate-II $\mathrm{Na}_{x} \mathrm{Si}_{136}$ upon heating under vacuum in the temperature range $350-450{ }^{\circ} \mathrm{C}$ [75]. Combining repeated heating under vacuum with density separation and/or reaction with iodine, the Na content can be reduced to ppm levels $[76,77]$. In this way, the new silicon allotrope $\mathrm{Si}(c F 136)$ is obtained, whose widened electronic band gap $[14,76]$ and significantly reduced thermal conductivity [22] can be attributed to the expanded clathrate crystal structure relative to $\alpha$-Si. While in principle a pristine clathrate should be able to be obtained, in practice, some small alkali metal content (sodium) typically remains.

The preparation of crystalline allotropes by thermal decomposition of M-Si and M-Ge Zintl precursors is accompanied by several challenges. Often, more than one phase can be obtained in the reaction products. For example, thermal decomposition of $\mathrm{Na}_{4} \mathrm{Si}_{4}$ often results in a micro or nanocrystalline mixture of clathrate-I $\mathrm{Na}_{8} \mathrm{Si}_{46}$, clathrate-II $\mathrm{Na}_{x} \mathrm{Si}_{136}$, as well as $\alpha$-Si and amorphous material [75]. Thermal decomposition of $\mathrm{Na}_{4} \mathrm{Ge}_{4}$ produces the zeolite-like Zintl phase $\mathrm{Na}_{4} \mathrm{Ge}_{13}[78,79]$ or clathrate-II $\mathrm{Na}_{x} \mathrm{Ge}_{136}$ depending on the decomposition conditions [80]. Recent improvements to thermal decomposition synthesis of these materials provide better control over the partial pressure of $\mathrm{Na}$, improving the phase selectivity and access to phase pure macroscopic single crystals of Si-based clathrates (Figure 4b) $[81,82]$. Preparations of silicon clathrates using Zintl phases as precursors in metal flux synthesis are also being developed [83], while employing $\mathrm{Na}_{4} \mathrm{Si}_{4}$ as a precursor in conjunction with $\mathrm{CsCl}$ or $\mathrm{KCl}$ resulted in Si clathrate-I and II phases [84,85]. 
(a)

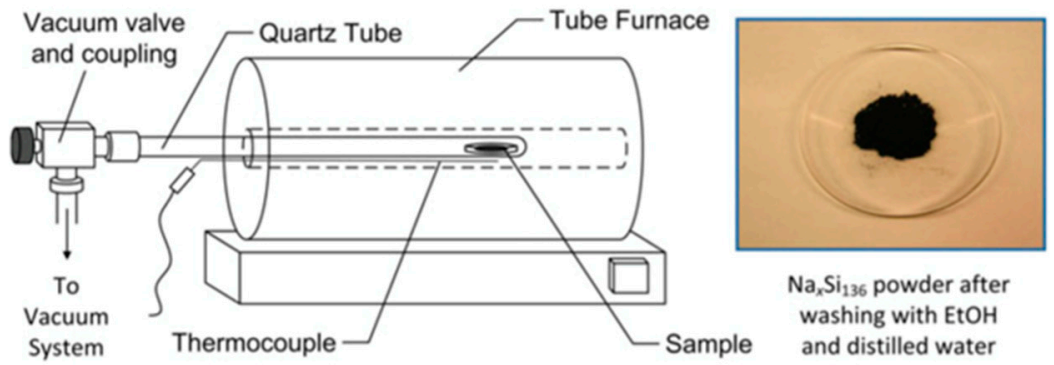

(b)

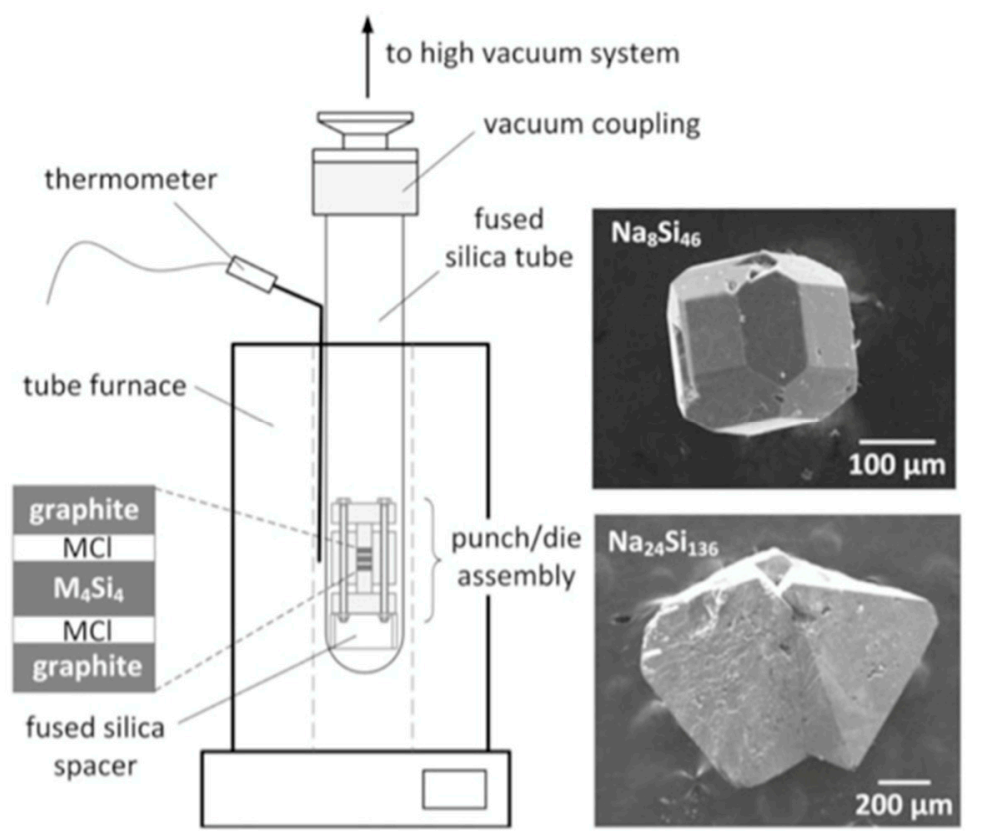

Figure 4. Two approaches to the synthesis of Na-Si clathrates (intermediates to Si clathrate modifications) by thermal decomposition of $\mathrm{Na}_{4} \mathrm{Si}_{4}$. The methods produce (a) microcrystalline and (b) single crystal products. In (b), the rate of thermal decomposition is controlled by maintaining a higher Na partial pressure (see [81]). Reproduced with permission from Nolas, G.S. (Copyright, 2014, Springer-Nature).

\subsection{Reaction Pathways}

All of the above synthetic approaches beg an important question-how do the isolated Si or Ge polyatomic anions in Zintl phase precursors transform into 3D 4-bonded frameworks upon oxidation? As with most solid-state reactions, in situ experimental data are sparse, and the detailed reaction mechanisms are not well understood. In one of the only in situ studies of the transformation of a tetrel-based Zintl phase into a tetrel-based framework, Hutchens et al. tracked the thermal decomposition of $\mathrm{Na}_{4} \mathrm{Si}_{4}$ to clathrate-I $\mathrm{Na}_{8} \mathrm{Si}_{46}$ using in situ synchrotron X-ray diffraction [86]. Despite the apparently disparate crystal structures of $\mathrm{Na}_{4} \mathrm{Si}_{4}$ (containing isolated $\left[\mathrm{Si}_{4}\right]^{4-}$ clusters) and $\mathrm{Na}_{8} \mathrm{Si}_{46}$ (nominally containing a 3D [ $\left.\mathrm{Si}_{46}\right]^{8-}$ 4-bonded framework), the authors found no evidence for any amorphous or crystalline intermediate phase. Rather, a large thermal expansion of the unit cell of $\mathrm{Na}_{4} \mathrm{Si}_{4}$ appears to enable a continuous transformation of one structure into another, accompanied by the simultaneous release of $\mathrm{Na}$ vapor from $\mathrm{Na}_{4} \mathrm{Si}_{4}$ [86]. Observed diffraction peaks common to both structures suggest a structural relationship between the two, though the exact relationship has not been elucidated.

The thermal behavior of Zintl precursors may be important in understanding the transformation that occurs in chemical synthesis routes as well. Future detailed in situ experiments, in particular those employing total scattering techniques [87], might yield important insight into the reaction pathways 
in the synthesis of silicon and germanium frameworks from Zintl precursors and how such routes might be extended to prepare other materials. Polyanion dynamics and cation diffusion pathways in the precursors and intermediates are also important but have thus far received relatively little attention [88-91].

\subsection{Other Opportunities}

The allotropes directly obtained from thermal or chemical treatment of Zintl phase precursors can also be further processed and transformed to yet other crystalline modifications. For example, m-allo-Ge transforms irreversibly to the $4 \mathrm{H}-\mathrm{Ge}$ phase upon heating to approximately $200{ }^{\circ} \mathrm{C}[52,92]$. The $4 \mathrm{H}-\mathrm{Ge}$ phase then transforms to $\alpha$-Ge near $400{ }^{\circ} \mathrm{C}$ [58]. Application of pressure to the low-density $\mathrm{Ge}(c F 136)$ clathrate modification yielded the discovery of a new allotrope, $\mathrm{Ge}(h R 8)$ [93].

The research described above provides a glimpse into the rich and complex free energy landscape for silicon and germanium elemental modifications and has revealed different ways that Zintl precursors can be utilized to access it. We conclude this section by noting that the chemical flexibility to prepare Zintl precursors having chemical substitutions on the tetrel sites provides even further opportunities to tune the properties of the resulting elemental modifications. For example, P-doping is possible on the Si sites of $\mathrm{Na}_{4} \mathrm{Si}_{4}$, which could in turn be used to dope a silicon modification derived from this precursor, e.g., $\mathrm{Si}(c F 136)$ [42]. The ability to prepare $\mathrm{Na}_{4}\left(\mathrm{Si}_{1-\mathrm{x}} \mathrm{Ge}_{\mathrm{x}}\right)_{4}$ precursors [43] has been utilized for the synthesis of silicon-germanium alloy clathrates via thermal decomposition [80,94], where the optical and transport properties can be tuned with the Si:Ge composition [95].

\section{Nanoporous and Mesostructured Networks}

Mesostructured and mesoporous materials have been of interest for some time [96], but mesostructured silicon and germanium materials have only recently gained more attention with the development of effective methods of synthesis for non-oxides. Nano- or meso-porous Ge was initially prepared from Zintl phases for porous optical and electronic applications [97-99] and, more recently, for potential applications in $\mathrm{Li}$ ion batteries [100]. Some of these results were reviewed relatively recently [25]. Nanoporous Ge can be prepared from dissolving solid " $\mathrm{K}_{2} \mathrm{Ge}_{9}$ " in ethylenediamine and mixing with cetyltriethylammonium bromide surfactant [97]. The dissolved $\left[\mathrm{Ge}_{9}{ }^{2-}\right]_{n}$ polymer was oxidized with ferrocenium hexafluorophosphate to form a dark colored solid. Nanoporous $\mathrm{Ge}_{1-x} \mathrm{Si}_{x}$ was prepared from $\mathrm{K}_{4} \mathrm{Ge}_{5} \mathrm{Si}_{4}$ following the same procedure. The TEM image of Figure 5 shows the nanoscale order with a hexagonal array of pores for the product. Nanoporous Ge can also be prepared from the reaction of $\mathrm{Mg}_{2} \mathrm{Ge}$ with $\mathrm{GeCl}_{4}$ in the presence of the amphiphilic surfactant $\mathrm{N}$-eicosane-N-methyl, N,N-dis(2-hydroxyethyl)ammonium bromide in formamide solution [98]. Figure 6 shows the high-resolution TEM and fast Fourier transform (FFT) as an inset, indicating the various orientations of cubic mesostructured germanium.
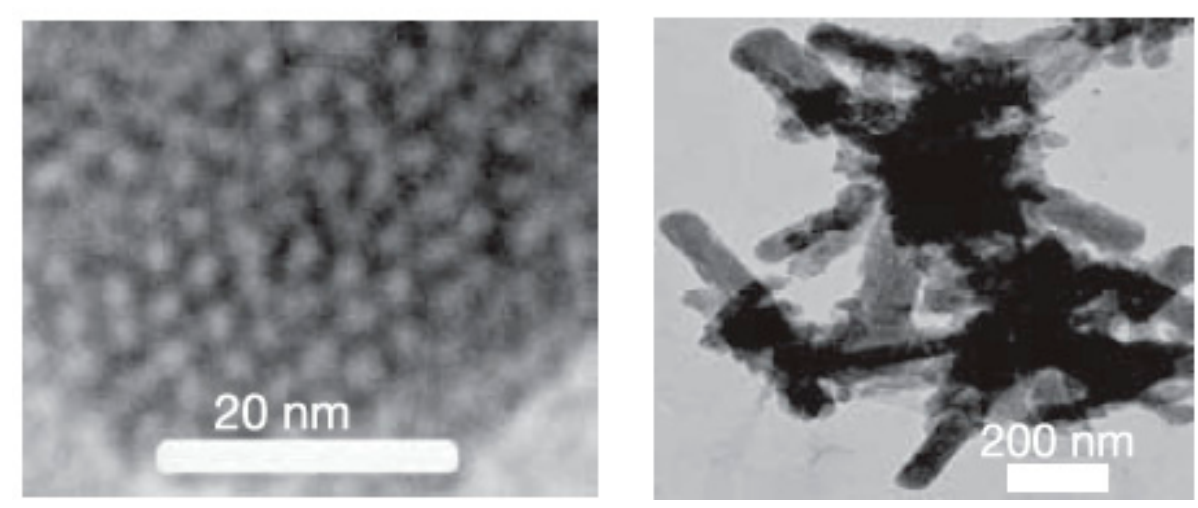

Figure 5. A view of the hexagonal array in a partly oxidized composite (left) and the particle shape of the product (right). Reprinted with permission from Sun, D. et al. (copyright, 2006, Nature). 

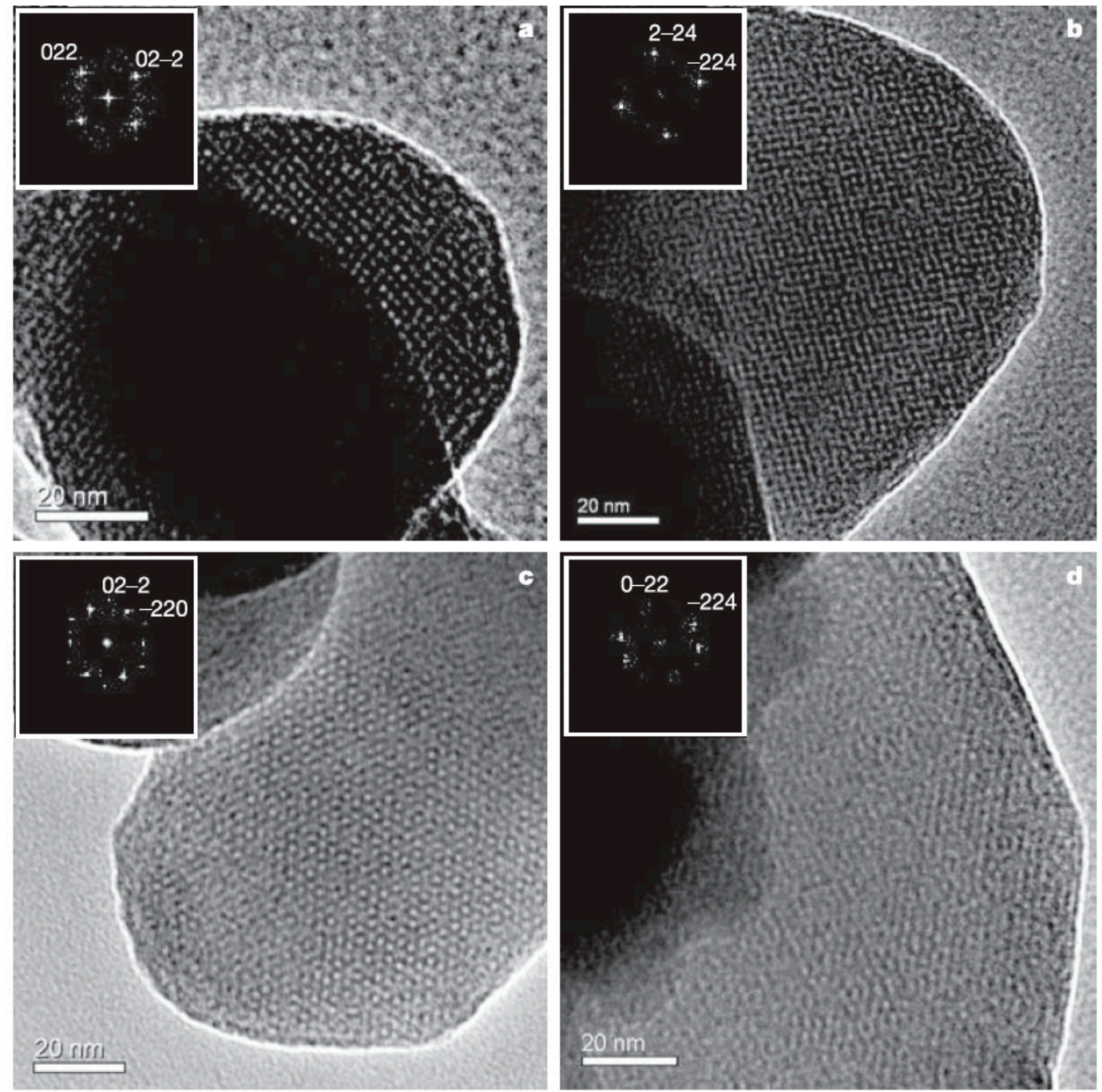

Figure 6. High-resolution TEM micrographs with fast Fourier transform (FFT) images as insets of mesoporous Ge prepared from $\mathrm{Mg}_{2} \mathrm{Ge}$ and $\mathrm{GeCl}_{4}$ taken along the [100] (a), the [110] (b), the [111] (c), and the [311] directions (d). Reproduced with permission from Armatas, G.S. et al. (copyright, 2006, Nature).

$\left[\mathrm{Ge}_{9}\right]^{4-}$ clusters have also been employed to make highly ordered porous frameworks $[100,101]$. Employing $\mathrm{K}_{4} \mathrm{Ge}_{9}$ as a soluble precursor in ethylenediamine and reacting with $\mathrm{SiCl}_{4}, \mathrm{GeCl}_{4}$, and $\mathrm{PCl}_{3}$ provides a Si and P-containing Ge mesoporous material, as demonstrated by powder X-ray diffraction, Raman spectroscopy, and energy-dispersive $X$-ray analysis. The main idea behind this work was to provide a homogeneous distribution of the Zintl phase $\mathrm{K}_{4} \mathrm{Ge}_{9}$ in a template mold and oxidize the $\left[\mathrm{Ge}_{9}\right]^{4-}$ clusters via a metathesis reaction, as illustrated in Figure 7 . The pores are templated by close-packed polymethylmethacrylate (PMMA) spheres, which yield Ge inverse opals upon removal. The authors demonstrated by Raman spectroscopy that the [Ge9] ${ }^{4-}$ remains intact as deposited, and the oxidation and removal of the salt and ethylenediamine result in amorphous Ge. Crystalline mesoporous Ge was obtained by heat treatment. Potential applications of such materials include hybrid solar cells and thin film anodes. 
a)

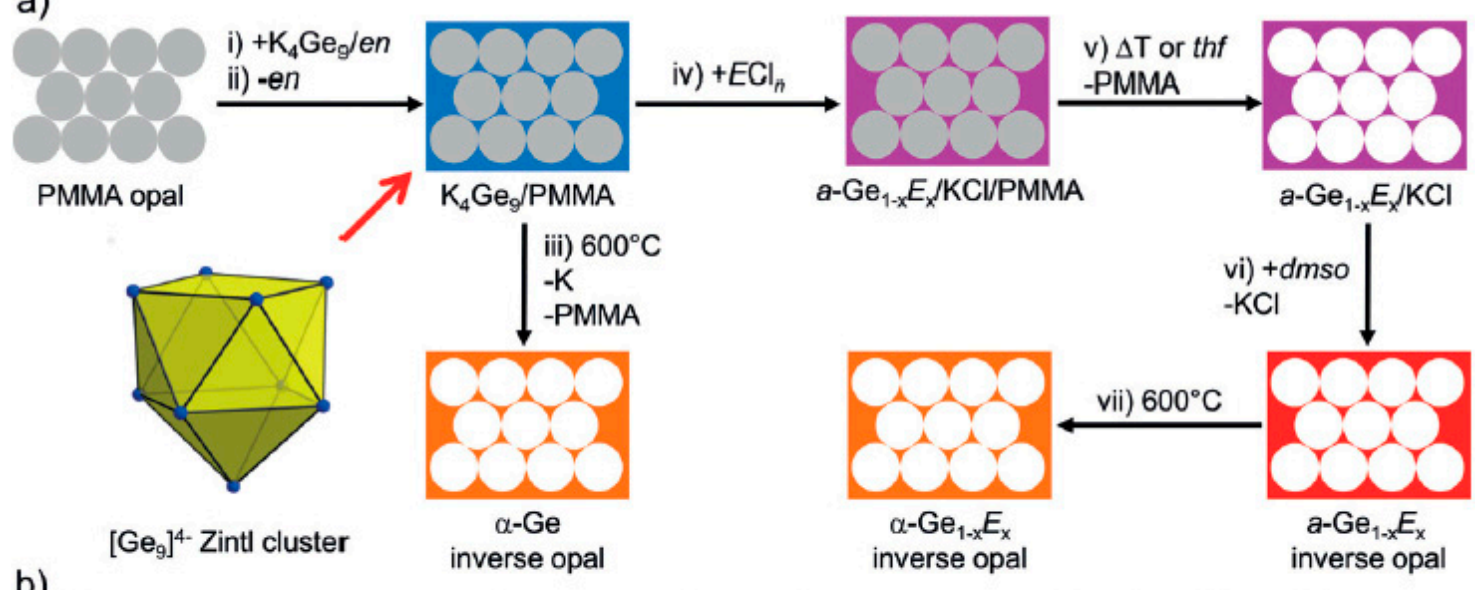

b)

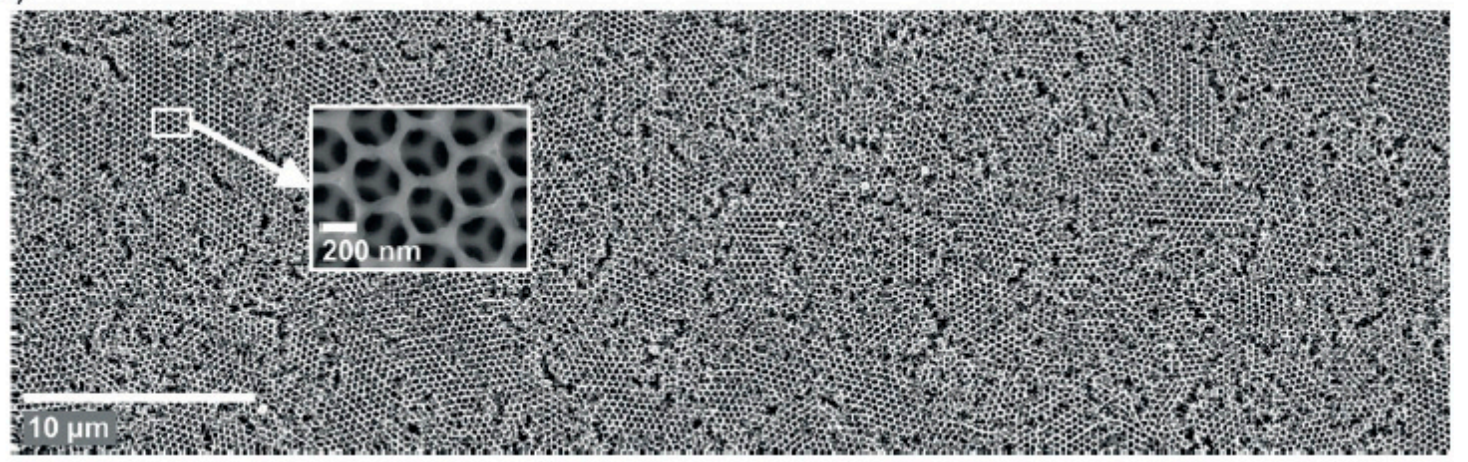

Figure 7. Schematic of the reaction to prepare mesoporous Ge by oxidation of $\mathrm{Ge}_{9}{ }^{4-}$ cluster (a) PMMA = polymethylmethacrylate, en = ethylenediamine. Scanning electron micrographs of Ge inverse opals with a magnified section indicated (b). Reproduced with permission Bentlohner, M.M. et al. (copyright, 2016, Angewandte Chemie International Edition).

\section{Nanoparticles and Other Nanostructures}

Si and Ge semiconductor nanomaterials have useful applications in many areas of technology and biology [102-105]. In principle, the band gap of these materials can be controlled by size and surface modification. While decreasing the size will increase the band gap, the mobility of charge carriers is controlled through doping with either donors or acceptors. Employing Zintl phase precursors allows for significant advantages in obtaining new morphologies and unique properties. While there have been a number of reviews in employing Zintl phases for new clusters and nanomaterials, there are relatively few that focus on use of silicide and germanide precursors to make Si and Ge nanomaterials $[28,33,106]$.

Both Si and Ge nanomaterials can be prepared by multiple methods and chemical routes, but employment of Zintl phase precursors offers a facile and low temperature method to prepare them. $\mathrm{Si}$ and Ge nanoparticles (NPs) with controlled size from approximately $10 \mathrm{~nm}$ to $2 \mathrm{~nm}$ in diameter can be prepared from Zintl phases. Depending upon the route, the inorganic surfaces are terminated by either halogens or hydrogen. Metathesis is a well-known route to new compounds [107] and has been employed for making Si and Ge NPs in solution [108-114], as well as other nanomaterials [115]. Oxidation of metal silicides with bromine in solution yields highly crystalline hexagonally shaped nanocrystals of $\mathrm{Si}$ [116]. Figure 8 shows crystalline Si nanoparticles prepared via the oxidation reaction of $\mathrm{Mg}_{2} \mathrm{Si}$ and $\mathrm{Br}_{2}$ in solution. Some of the crystallites in the image have the expected hexagonal shape of diamond structured $\mathrm{Si}$. Oxidation of $\mathrm{Na}_{4} \mathrm{Si}_{4}$ with alcohols shows that various morphologies of nanomaterials can be obtained [117]. The oxidation ability of the various alcohols provides either crystalline or amorphous materials, as shown in Figure 9. Short chain alkyls give rise to crystalline products, as shown in the selected area electron diffraction (SAED) patterns shown in the insets for 
each sample. The morphology of the final product was dictated by the reduction ability of the alcohol. The nanoparticles obtained from ethanol were $15 \pm 4 \mathrm{~nm}$ in diameter, whereas those obtained from 1-butanol were smaller (11 $\pm 4 \mathrm{~nm})$. Benzyl alcohol and 1-octanol gave large submicron sheets of amorphous materials. The effect of alcohol oxidation is also noted in metathesis reactions. For example, in the reaction of $\mathrm{Mg}_{2} \mathrm{Si}$ with $\mathrm{SiI}_{4}$ [115], the authors found that nanowires of Si could be prepared in quantitative yield by adding a small amount of ethanol. The probable reaction is the initial oxidation of $\mathrm{Mg}_{2} \mathrm{Si}$ to $\mathrm{MgO}$ and $\mathrm{SiH}_{4}+\mathrm{C}_{2} \mathrm{H}_{2}$ and the heat released from this reaction drives the decomposition of $\mathrm{SiI}_{4}$ to $\mathrm{Si}$ and $\mathrm{I}_{2}$. The presence of $\mathrm{I}_{2}$ may contribute as a vapor transport agent, as the authors document that iodine gas is produced by the reaction. The authors also investigated other alcohols but found that branched alcohols did not have the same effect. This may be similar to results described above for alcohol oxidation; further research might provide a simple, effective way to obtain high yields of Si in particular morphologies. Similar to oxidation with alcohols, metal silicides and germanides can be transformed to nanomaterials by the application of ammonium halides [118], $\mathrm{NH}_{4} \mathrm{X}$, to prepare Si and Ge nanomaterials [119-122], providing an easy route to high yields of Si and Ge nanomaterials.

Transition metal doped and P doped Si NPs have been prepared by a reaction of metal or phosphorus doped $\mathrm{Na}_{4} \mathrm{Si}_{4}$ with $\mathrm{NH}_{4} \mathrm{Br}$ in solution [43,123-127]. Metal hydrides mixed with $\mathrm{Si}$ or Ge are reacted under an argon flow at low temperature to provide high purity $\mathrm{A}_{4} \mathrm{Si}_{4}$ and $\mathrm{A}_{4} \mathrm{Ge}_{4}$ $(\mathrm{A}=\mathrm{Na}, \mathrm{K})$. To prepare doped $\mathrm{Si}$ and Ge nanomaterials, transition metal precursors such as metal acetylacetonates (or the element in the case of phosphorus [42]) are ball milled with Si according to Figure 10 [46] or Ge into a well dispersed fine powder and reacted with the metal hydride to form the metal silicide or germanide Zintl phase. These Zintl phases can then be employed with any of the reactions described above to make nanoparticles. The metal doped nanoparticles are characterized by TEM, X-ray powder diffraction, UV-Vis spectroscopy, photoluminescence, transient absorption spectroscopy, and electron paramagnetic resonance [125,126]. TEM analysis shows that the particles are crystalline, Figure 11. These nanoparticles have found applications as biocompatible and biodegradable multimodal agents [127-130]. In many cases, the yield of well capped crystalline NPs is low $[105,121,131]$, but for other applications, such as Li ion batteries, amorphous products are better, and oxidation routes lead to different morphologies in quantitative yield [101,117].

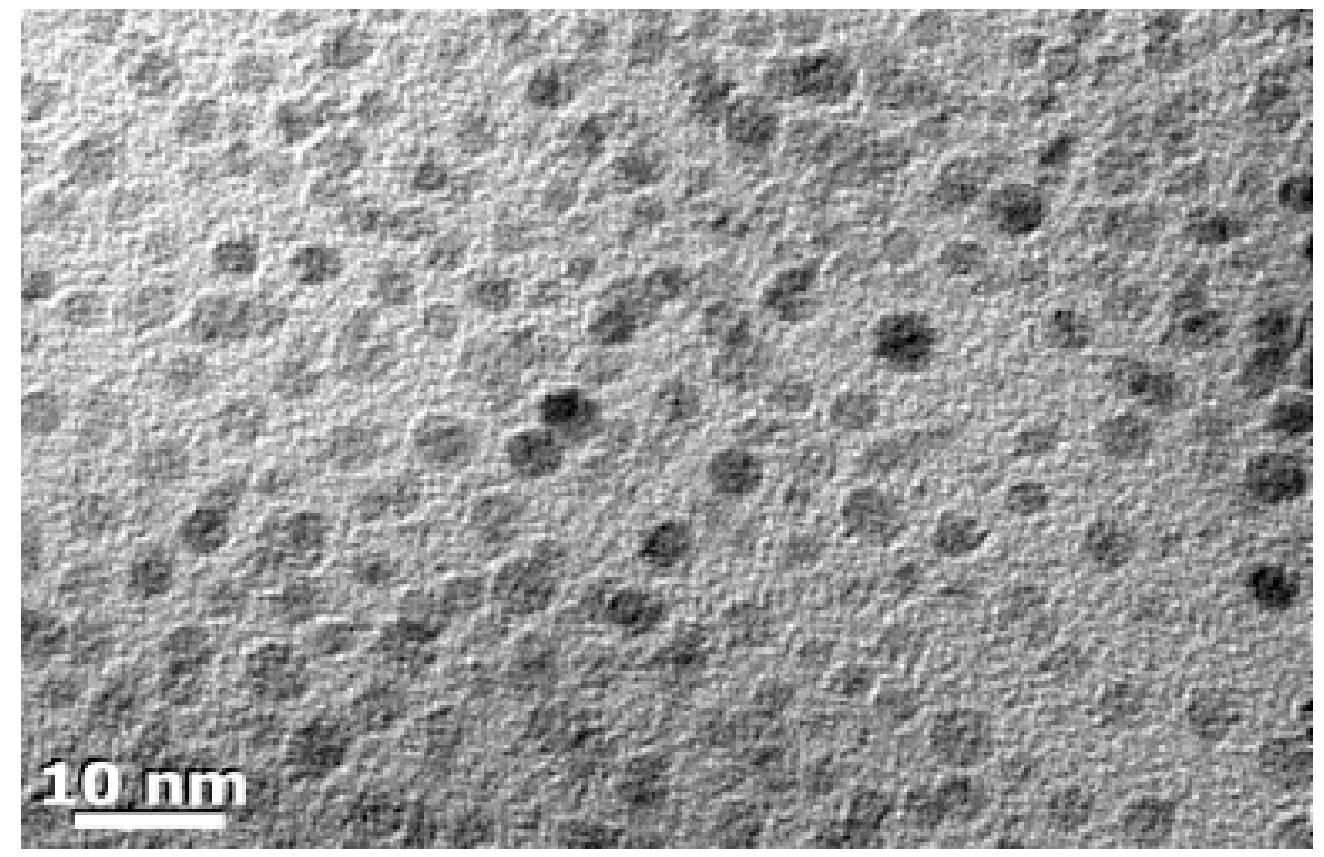

Figure 8. TEM micrograph of $\mathrm{Si}$ nanoparticles prepared from the reaction of $\mathrm{Mg}_{2} \mathrm{Si}_{\text {ith }} \mathrm{Br}_{2}$ in 1,2-dimethoxyethane and are alkyl-/alkoxy-capped. Reproduced with permission from Pettigrew, A. et al. (copyright, 2003, American Chemical Society). 

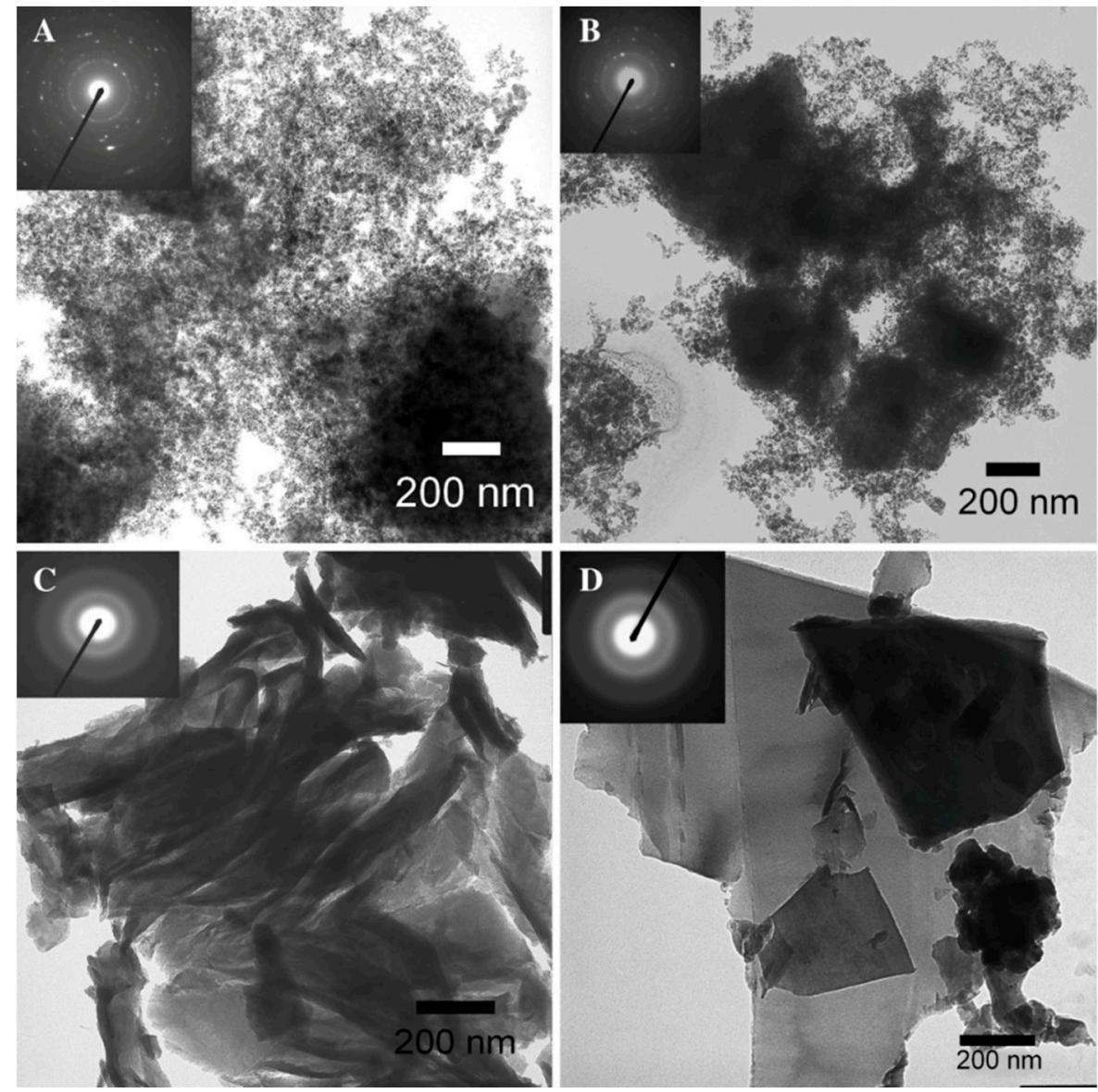

Figure 9. TEM micrographs [insets of selected area electron diffraction (SAED) for the samples] of $\mathrm{Si}$ nanoparticles prepared from the reaction of $\mathrm{Na}_{4} \mathrm{Si}_{4}$ with ethanol (A); 1-butanol (B); benzyl alcohol (C); 1-octanol (D). Reproduced from Oxidation pathways towards Si amorphous layers or nanocrystalline powders as Li-ion batteries anodes. Reproduced with permission from Annou, K. et al. (copyright, 2014, Materials for Renewable and Sustainable Energy).
(a) $\mathrm{NaH}+\mathrm{Si}+\mathrm{Mn}$
$\underset{500^{\circ} \mathrm{C} 24 \text { hours }}{\stackrel{420^{\circ} \mathrm{C} 48 \text { hours }}{\longrightarrow}} \mathrm{Na}_{4} \mathrm{Si}_{4 \mathrm{Mn}}+\mathrm{Mn}_{\mathrm{x}} \mathrm{Si}_{\mathrm{y}}+\mathrm{H}_{2} \uparrow$
(b) $\mathrm{NaH}+\mathrm{Si}+\mathrm{Mn}(\mathrm{acac})_{2}$
$\underset{500^{\circ} \mathrm{C} 24 \text { hours }}{\stackrel{420^{\circ} \mathrm{C} 48 \text { hours }}{\longrightarrow}} \mathrm{Na}_{4} \mathrm{Si}_{4 \mathrm{Mn}}+\mathrm{Mn}_{\mathrm{x}} \mathrm{Si}_{\mathrm{y}}+\mathrm{Si}+\mathrm{CO} \uparrow+\mathrm{C}_{2} \mathrm{H}_{6} \uparrow+\mathrm{CH}_{4} \uparrow+\mathrm{H}_{2} \uparrow$
(c) $\mathrm{Na}_{4} \mathrm{Si}_{4 \mathrm{Mn}}+\mathrm{NH}_{4} \mathrm{Br}$
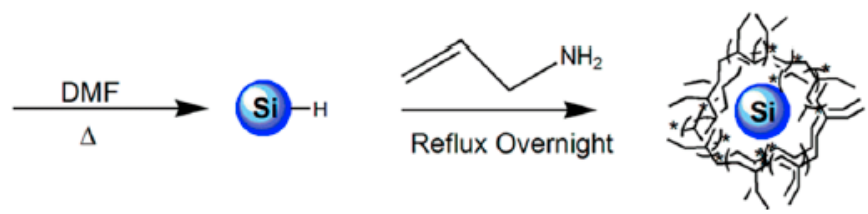

Figure 10. Reaction schemes for $\mathrm{Mn}$ doped $\mathrm{Na}_{4} \mathrm{Si}_{4}$ with $\mathrm{Mn}$ metal (a) $\mathrm{Mn}^{\mathrm{II}}$ acetylacetonate (b) and the reaction scheme to form Mn doped Si nanoparticles (c). Reproduced from EPR and Structural Characterization of Water-Soluble $\mathrm{Mn}^{2+}$-Doped Si Nanoparticles. (copyright, 2017, The Journal of Physical Chemistry C). 

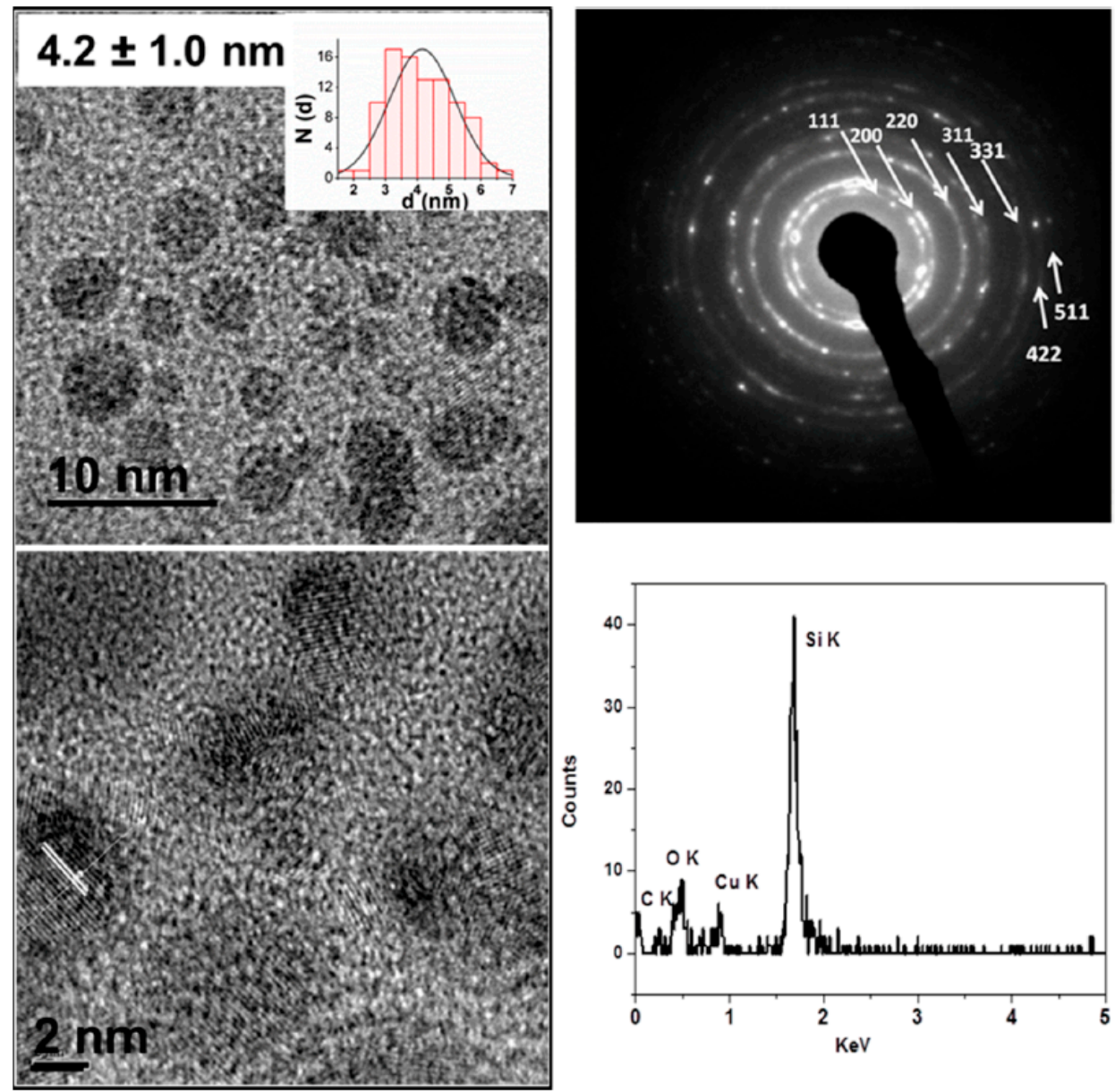

Figure 11. TEM images of Mn-doped Si nanoparticles with a histogram (top, left) and a high resolution TEM (bottom, left) with the (220) lattice plane indicated, Selected area electron diffraction (top, right) and energy dispersive X-ray spectroscopy (EDS) of the sample (bottom, right). The concentration of Mn was not sufficiently high to be observed in the EDS spectrum. Reproduced from EPR and Structural Characterization of Water-Soluble $\mathrm{Mn}^{2+}$-Doped Si Nanoparticles. (copyright, 2017, The Journal of Physical Chemistry C).

Zintl phases containing group 14 elements in 2D layers have also been studied as precursors to unique layered materials that can be described as group 14 analogs of graphane, e.g., silicane and germane. Progress in this area was recently reviewed [106]. While we briefly highlight more recent work on oxidation of Zintl phases with alcohols, initial studies were conducted as early as the 1860 s to prepare silicon sheets by the oxidation of $\mathrm{CaSi}_{2}$ (accompanied by removal of $\mathrm{Ca}$ from the structure) by $\mathrm{HCl}$. The silicon layered material consists of a two-dimensional silicon backbone structure with stoichiometries of $\left[\mathrm{Si}_{6} \mathrm{H}_{3}(\mathrm{OH})_{3}\right]_{n}$ and $\left[\mathrm{Si}_{6} \mathrm{H}_{6-x}(\mathrm{OH})_{1-x}\right]_{n}(x<1)$ depending on the reaction conditions $[132,133]$. These materials are considered to be puckered silicon layers with either terminal hydrogens and/or hydroxides [134]. Interestingly, they show direct bandgaps and photoluminescence.

The above chemistry has also been extended to germanium, initially employing $\mathrm{HCl}$ [135]. More recently, this route has been scaled and demonstrated with large single crystals of $\mathrm{CaGe}_{2}$. Figure 12 shows the chemical reaction and the $\mathrm{CaGe}_{2}$ crystals with the product of $\mathrm{GeH}$ [136]. Since Zintl phases can be prepared with various amounts of the group 14 elements, this synthetic route has been expanded to include novel $\mathrm{Ge}_{1-x} \mathrm{Sn}_{x} 2 \mathrm{D}$ materials and more exotic group 14 materials [106]. The research on these novel 2D materials is still in its infancy, and the possibility of many combinations and chemical modifications is expected to stimulate more work on these materials, which may possess novel electronic and optical properties. 

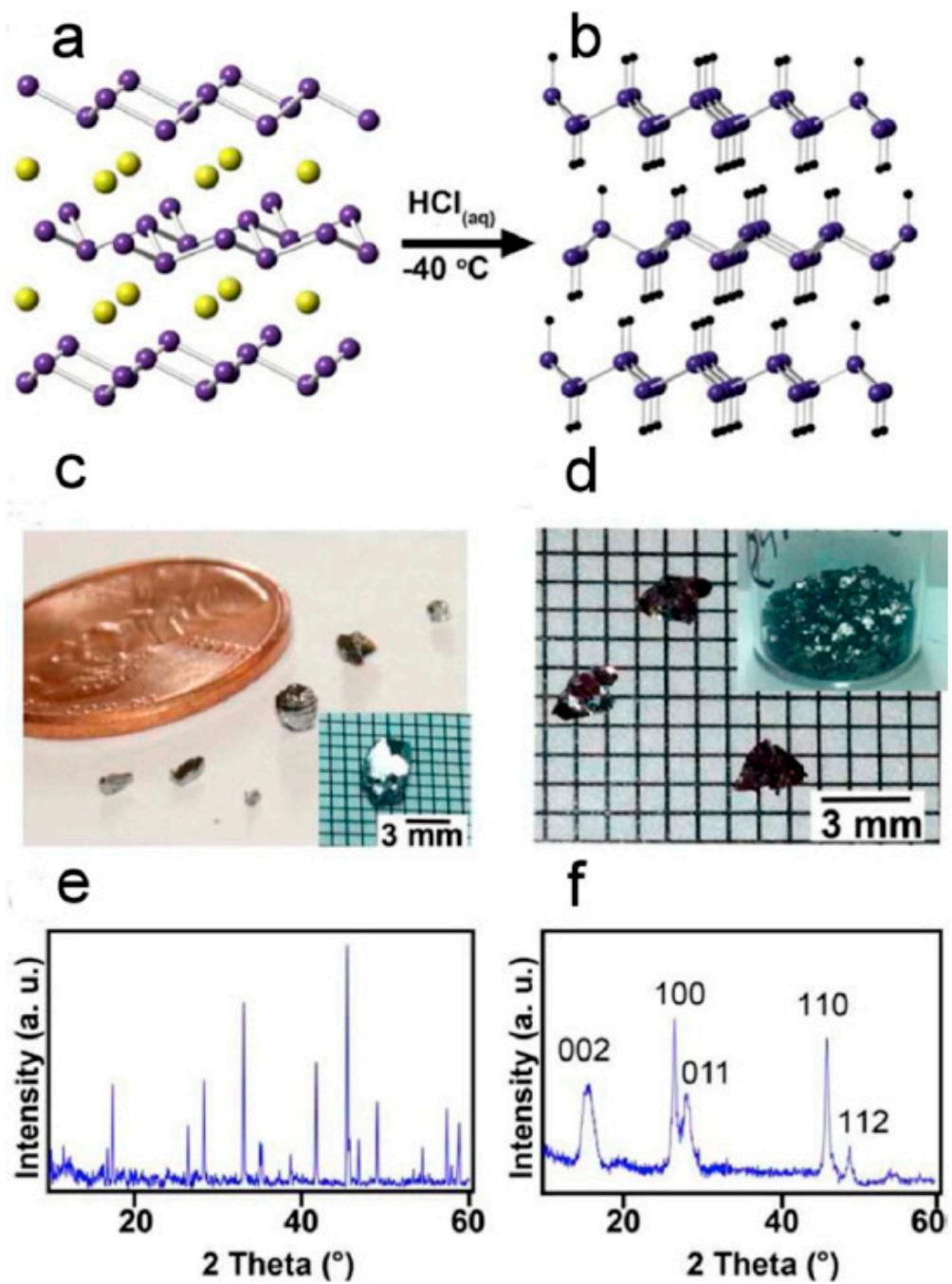

Figure 12. Illustration of the oxidation and deintercalation of $\mathrm{CaGe}_{2}$ (a) to $\mathrm{GeH}(\mathbf{b})$. Crystals of $\mathrm{CaGe}_{2}$ (c) and $\mathrm{GeH}(\mathbf{d})$ and powder X-ray diffraction of $\mathrm{CaGe}_{2}$ (e) and $\mathrm{GeH}(\mathbf{f})$. Reproduced with permission of Bianco, E. et al. (copyright, 2013, ACS Nano).

\section{Outlook}

The above examples illustrate the richness in novel silicon and germanium-based materials that can be prepared by thermal and chemical treatment of Zintl precursors containing these elements. A key feature of silicon and germanium-based Zintl phases that makes them particularly useful as precursors for synthesis of metastable materials is the presence of various reactive, covalently bonded anionic subunits, which can be oxidized to form 3D networks as well as a variety of nanostructures. Although in some cases the reaction pathways can be readily inferred by recognizing similarities between the features of the crystal structure of the precursor and the structure and bonding topology of the product, the concept of how polyanions in Zintl precursors transform to 4-bonded Si and Ge networks is still not well understood. In general, the product that will be produced by chemical or thermal treatment of a particular Zintl phase cannot easily be predicted a priori. This highlights the need for detailed in situ studies and additional theoretical work to better understand reaction pathways and mechanisms underlying the transformation of the Zintl precursors to crystalline modifications and other extended solids.

Inasmuch as chemical oxidation has proven a very effective approach to obtaining new materials from Zintl precursors, electrochemical oxidation also holds significant promise but as yet remains relatively underexplored. Work by Chandrasekharan and Sevov demonstrated that 
amorphous germanium films can be deposited anodically at room temperature by a relatively simple electrochemical process using $\mathrm{K}_{4} \mathrm{Ge}_{9}$ precursors dissolved in ethylenediamine [137]. Scherf et al. have demonstrated that allo-Ge can also be electrochemically prepared from $\mathrm{Li}_{12} \mathrm{Ge}_{17}$ [138]. On the other hand, macroscopic single crystals of clathrate-II $\mathrm{Na}_{24} \mathrm{Si}_{136}$ [139] and other silicon clathrates [140] are obtained by field assisted sintering of $\mathrm{Na}_{4} \mathrm{Si}_{4}$ at $600{ }^{\circ} \mathrm{C}$ under uniaxial pressure (so-called spark plasma sintering). Directed growth of $\mathrm{Na}_{24} \mathrm{Si}_{136}$ at the anode and accumulation of metallic $\mathrm{Na}$ at the cathode is suggestive of an influence of the electric current and solid-state electrochemical reaction. Such results hint at the potential of electrochemical reactions as applied to Zintl precursors, which would enable a greater variety of experimental parameters that can be used to direct the formation of specific products. Such approaches clearly deserve further study.

In closing, the research reviewed here has shown that Zintl precursors can be transformed into new materials via thermal treatment and metathesis reactions as well as solution, gaseous, and electrochemical oxidation. Perhaps other approaches, e.g., microwave synthesis, could be employed as well. While there has been progress in all areas, more rapid advances are expected once the various reaction pathways and mechanisms are better understood. We expect continued efforts will enable new and novel phases with interesting and perhaps useful properties while advancing the understanding of reaction mechanisms in solid-state chemistry in general.

Author Contributions: Conceptualization, M.B., S.M.K. and G.S.N.; Writing-Original Draft Preparation, M.B. and S.M.K.; Writing-Review \& Editing, M.B., S.M.K., L.D. and G.S.N.; Visualization, M.B., S.M.K. and L.D.; Supervision, M.B.; Funding Acquisition, M.B., S.M.K., and G.S.N.

Funding: Matt Beekman and Luke Doherty gratefully acknowledge support from the William and Linda Frost Fund. George S. Nolas acknowledges support from the National Science Foundation (NSF) Grant No. DMR-1748188. Susan M. Kauzlarich acknowledges NSF Grant No. CHE-1710110 for funding.

Conflicts of Interest: The authors declare no conflict of interest.

\section{References}

1. Seitz, F.; Einspruch, N.G. Electronic Genie: The Tangled History of Silicon; University of Illinois Press: Urbana and Chicago, IL, USA, 1998.

2. Bosi, M.; Attolini, G. Germanium: Epitaxy and its applications. Prog. Cryst. Growth Charact. Mater. 2010, 56, 146-174. [CrossRef]

3. Greenwood, M.N.; Earnshaw, A. Chemistry of the Elements, 2nd ed.; Elsevier Publishing: Oxford, UK, 1997.

4. Taylor, P.C. Exotic forms of silicon. Phys. Today 2016, 69, 34-39. [CrossRef]

5. Beekman, M. New hopes for allotropes. Mater. Today 2015, 18, 304-305. [CrossRef]

6. Beekman, M.; Wei, K.; Nolas, G.S. Clathrates and beyond: Low-density allotropy in crystalline silicon. Appl. Phys. Rev. 2016, 3, 1-8. [CrossRef]

7. Haberl, B.; Strobel, T.A.; Bradby, J.E. Pathways to exotic metastable silicon allotropes. Appl. Phys. Rev. 2016, 3, 040808. [CrossRef]

8. Kim, D.Y.; Stefanoski, S.; Kurakevych, O.O.; Strobel, T.A. Synthesis of an open-framework allotrope of Silicon. Nat. Mater. 2014, 14, 169-173. [CrossRef] [PubMed]

9. Fässler, T.F. Germanium(cF136): A new crystalline modification of Germanium with the porous clathrate-II structure. Angew. Chem. Int. Ed. 2007, 46, 2572-2575. [CrossRef] [PubMed]

10. Street, R.A. (Ed.) Technology and Applications of Amorphous Silicon; Springer: Heidelberg, Germany, 2000.

11. Priolo, F.; Gregorkiewicz, T.; Galli, M.; Krauss, T.F. Silicon nanostructures for photonics and photovoltaics. Nat. Nanotechnol. 2014, 9, 19-32. [CrossRef]

12. Hea, Y.; Fanc, C.; Lee, S.-T. Silicon nanostructures for bioapplications. Nano Today 2010, 5, 282-295. [CrossRef]

13. Cullis, A.G.; Canham, L.T. Visible light emission due to quantum size effects in highly porous crystalline silicon. Nature 1991, 353, 335-338. [CrossRef]

14. Adams, G.B.; O'Keeffe, M.; Demkov, A.A.; Sankey, O.F.; Huang, Y.-M. Wide-band-gap Si in open fourfold-coordinated clathrate structures. Phys. Rev. B 1994, 49, 8048-8053. [CrossRef]

15. Wolkin, M.V.; Jorne, J.; Fauchet, P.M. Electronic states and luminescence in porous Silicon quantum dots: The role of Oxygen. Phys. Rev. Lett. 1999, 82, 197-200. [CrossRef] 
16. Zwijnenburg, M.A.; Jelfsab, K.E.; Bromley, S.T. An extensive theoretical survey of low-density allotropy in silicon. Phys. Chem. Chem. Phys. 2010, 12, 8505. [CrossRef] [PubMed]

17. Amsler, M.; Botti, S.; Marques, M.A.L.; Lenosky, T.J.; Goedecker, S. Low-density silicon allotropes for photovoltaic applications. Phys. Rev. B 2015, 92, 014101. [CrossRef]

18. Botti, S.; Flores-Livas, J.A.; Amsler, M.; Goedecker, S.; Marques, M.A.L. Low-energy silicon allotropes with strong absorption in the visible for photovoltaic applications. Phys. Rev. B 2012, 86, 121204R. [CrossRef]

19. Karttunen, A.J.; Fässler, T.F.; Linnolahti, M.; Pakkanen, T.A. Structural Principles of Semiconducting Group 14 Clathrate Frameworks. Inorg. Chem. 2011, 50, 1733. [CrossRef] [PubMed]

20. Zhao, Z.; Zhang, H.; Kim, D.Y.; Hu, W.; Bullock, E.S.; Strobel, T.A. Properties of the exotic metastable ST12 germanium allotrope. Nat. Commun. 2017, 8, 13909. [CrossRef]

21. Beekman, M.; Kaduk, J.A.; Wong-Ng, W.; Troesch, M.; Lee, G.S.; Nolas, G.S. Control of thermal expansion in a low-density framework modification of silicon. Appl. Phys. Lett. 2018, 112, 181901. [CrossRef]

22. Nolas, G.S.; Beekman, M.; Gryko, J.; Lamberton, G.A., Jr.; Tritt, T.M.; McMillan, P.F. Thermal conductivity of the elemental crystalline silicon clathrate $\mathrm{Si}_{136}$. Appl. Phys. Lett. 2003, 82, 910. [CrossRef]

23. Langer, T.; Dupke, S.; Trill, H.; Passerini, S.; Eckert, H.; Pöttgen, R.; Winter, M. Electrochemical Lithiation of Silicon Clathrate-II. J. Electrochem. Soc. 2012, 159, A1318-A1322. [CrossRef]

24. Yang, J.; Tse, J.S. Silicon clathrates as anode materials for lithium ion batteries? J. Mater. Chem. A 2013, 1, 7782-7789. [CrossRef]

25. Armatas, G.S.; Kanatzidis, M.G. Germanium-Based Porous Semiconductors from Molecular Zintl Anions. In Zintl Ions: Principles and Recent Developments; Fässler, T.F., Ed.; Springer: Heidelberg, Germany, 2011; pp. 133-154.

26. Schäfer, H.; Eisenmann, B.; Müller, W. Zintl Phases: Transitions between Metallic and Ionic Bonding. Angew. Chem. Int. Ed. 1973, 12, 694-712. [CrossRef]

27. Kauzlarich, S.M. (Ed.) Chemistry, Structure, and Bonding of Zintl Phases and Ions; VCH Publishers, Inc.: New York, NY, USA, 1996.

28. Fässler, T.F. (Ed.) Zintl Ions: Principles and Recent Developments; Springer: Berlin/Heidelberg, Germany, 2014; Volume 140.

29. Schäfer, H. On the problem of polar intermetallic compounds: The stimulation of E. Zintl's work for the modern chemistry of intermetallics. Ann. Rev. Mater. Sci. 1985, 15, 1-41. [CrossRef]

30. Sevov, S.C. Zintl phases. In Intermetallic Compounds: Volume 3, Principles and Practice; Westbrook, J.H., Fleischer, R.L., Eds.; John Wiley \& Sons, Ltd.: Hoboken, NJ, USA, 2000.

31. Corbett, J.D. Polyatomic Zintl Ions of the Post-Transition Elements. Chem. Rev. 1985, 85, 383-397. [CrossRef]

32. Scharfe, S.; Kraus, F.; Stegmaier, S.; Schier, A.; Fässler, T.F. Zintl Ions, Cage Compounds, and Intermetalloid Clusters of Group 14 and Group 15 Elements. Angew. Chem. Int. Ed. 2011, 50, 3630-3670. [CrossRef]

33. Kauzlarich, S.M. Transition Metal Zintl Compounds. In Chemistry, Structure, and Bonding of Zintl Phases and Ions; Kauzlarich, S.M., Ed.; VCH Publishers, Inc.: New York, NY, USA, 1996; pp. 245-274.

34. Kauzlarich, S.M.; Chan, J.Y.; Taylor, B.R. Exploitation of Zintl Phases in the Pursuit of Novel Magnetic and Electronic Materials. In Inorganic Materials Synthesis; ACS Symposium Series; Winter, C.H., Hoffman, D.M., Eds.; American Chemical Society: Washington, DC, USA, 1999; Volume 727, pp. 15-27.

35. Kauzlarich, S.M.; Brown, S.R.; Snyder, G.J. Zintl phases for thermoelectric devices. Dalton Trans. 2007, 21, 2099-2107. [CrossRef]

36. Toberer, E.S.; May, A.F.; Snyder, G.J. Zintl Chemistry for Designing High Efficiency Thermoelectric Materials. Chem. Mater. 2010, 22, 624-634. [CrossRef]

37. Beretta, D.; Neophytou, N.; Hodges, J.M.; Kanatzidis, M.G.; Narducci, D.; Martin-Gonzalez, M.; Beekman, M.; Balke, B.; Cerritti, G.; Tremel, W.; et al. Thermoelectrics: From history, a window on the future. Mater. Sci. Eng. $R$ 2018, in press. [CrossRef]

38. Mayer, K.; Wessing, J.; Fässler, T.F.; Fischer, R.A. Intermetalloid Clusters: Molecules and Solids in a Dialogue. Angew. Chem. Int. Ed. 2018, 57, 14372-14393. [CrossRef]

39. Downie, C.; Tang, Z.; Guloy, A.M. An unprecedented ${ }_{\infty}^{1}\left[\mathrm{Ge}_{9}\right]^{2-}$ polymer: A link between molecular Zintl clusters and solid-state phases. Angew. Chem. Int. Ed. 2000, 39, 338-340. [CrossRef]

40. Fässler, T.F. Homoatomic polyhedra as structural modules in chemistry: What binds fullerenes and homonuclear Zintl ions? Angew. Chem. Int. Ed. 2001, 40, 4161-4165. [CrossRef] 
41. Karttunen, A.J.; Fässler, T.F.; Linnolahti, M.; Pakkanen, T.A. Two-, one-, and zero-dimensional elemental nanostructures based on Geg-clusters. Chem. Phys. Chem. 2010, 11, 1944-1950. [CrossRef]

42. Wang, J.; Sen, S.; Yu, P.; Browning, N.D.; Kauzlarich, S.M. Synthesis and spectroscopic characterization of P-doped $\mathrm{Na}_{4} \mathrm{Si}_{4}$. J. Solid State Chem. 2010, 183, 2522-2527. [CrossRef]

43. Morito, H.; Momma, K.; Yamane, H. Crystal structure analysis of $\mathrm{Na}_{4} \mathrm{Si}_{4-x} \mathrm{Ge}_{x}$ by single crystal X-ray diffraction. J. Alloys Compd. 2015, 623, 473-479. [CrossRef]

44. Corbett, J.D. Solid State Chemistry Techniques; Cheetham, A.K., Day, P., Eds.; Oxford Science Publications: Oxford, UK, 1990.

45. Bobev, S.; Sevov, S. Clathrates of Group 14 with Alkali Metals: An Exploration. J. Solid State Chem. 2000, 153, 92-105. [CrossRef]

46. Ma, X.; Xu, F.; Atkins, T.M.; Goforth, A.M.; Neiner, D.; Navrotsky, A.; Kauzlarich, S.M. A versatile low temperature synthetic route to Zintl phase precursors: $\mathrm{Na}_{4} \mathrm{Si}_{4}, \mathrm{Na}_{4} \mathrm{Ge}_{4}$ and $\mathrm{K}_{4} \mathrm{Ge}_{4}$ as examples. Dalton Trans. 2009, 2009, 10250-10255. [CrossRef] [PubMed]

47. Zeilinger, M.; Jantke, L.-A.; Scherf, L.M.; Kiefer, F.J.; Neubüser, G.; Kienle, L.; Karttunen, A.J.; Konar, S.; Häussermann, U.; Fässler, T.F. Alkali metals extraction reactions with the silicides $\mathrm{Li}_{15} \mathrm{Si}_{4}$ and $\mathrm{Li}_{3} \mathrm{NaSi}_{6}$ : Amorphous Si versus allo-Si. Chem. Mater. 2014, 26, 6603-6612. [CrossRef]

48. Schwarz, U. Metallic high-pressure modifications of main group elements. Z. Kristallogr. 2004, 219, 376-390. [CrossRef]

49. Wentorf, R.H.; Kasper, J.S. Two New Forms of Silicon. Science 1963, 139, 338. [CrossRef]

50. Duclos, S.J.; Vohra, Y.K.; Ruoff, A.L. Experimental study of the crystal stability and equation of state of Si to 248 GPa. Phys. Rev. B 1990, 41, 12021. [CrossRef]

51. McMahon, M.I.; Nelmes, R.J. New high-pressure phase of Si. Phys. Rev. B 1993, 47, 8337. [CrossRef]

52. Grüttner, A.; Nesper, R.; von Schnering, H.G. Novel Metastable Germanium Modifications allo-Ge and 4H-Ge from $\mathrm{Li}_{7} \mathrm{Ge}_{12}$. Angew. Chem. Int. Ed. 1982, 21, 912. [CrossRef]

53. von Schnering, H.G.; Schwarz, M.; Nesper, R. The lithium sodium silicide $\mathrm{Li}_{3} \mathrm{NaSi}_{6}$ and the formation of allo-silicon. J. Less-Common Met. 1988, 137, 297. [CrossRef]

54. Conesa, J.C. Computer modeling of allo-Si and allo-Ge polymorphs. J. Phys. Chem. B 2002, 106, 3402-3409. [CrossRef]

55. Chadi, D.J. New crystalline structures for Si and Ge. Phys. Rev. B 1985, 32, 6485-6489. [CrossRef]

56. Kiefer, F.; Karttunen, A.J.; Döblinger, M.; Fässler, T.F. Bulk synthesis and structure of a microcrystalline allotrope of Germanium (m-allo-Ge). Chem. Mater. 2011, 23, 4578-4586. [CrossRef]

57. Kiefer, F.; Fässler, T.F. Synthesis and revised structure of the Zintl phase $\mathrm{Li}_{7} \mathrm{Ge}_{12}$. Solid State Sci. 2011, 13, 636-640. [CrossRef]

58. Zaikina, J.V.; Muthuswamy, E.; Lilova, K.I.; Gibbs, Z.M.; Zeilinger, M.; Snyder, G.J.; Fässler, T.F.; Navrotsky, A.; Kauzlarich, S.M. Thermochemistry, morphology, and optical characterization of Germanium allotropes. Chem. Mater. 2014, 26, 3263-3271. [CrossRef]

59. Tang, Z.; Litvinchuk, A.P.; Gooch, M.; Guloy, A.M. A narrow gap semiconducting Germanium allotrope from the oxidation of a layered Zintl phase in ionic liquids. J. Am. Chem. Soc. 2018, 140, 6785-6788. [CrossRef]

60. Guloy, A.M.; Ramlau, R.; Tang, Z.; Schnelle, W.; Baitinger, M.; Grin, Y. A guest-free germanium clathrate. Nature 2006, 443, 320-323. [CrossRef]

61. Nolas, G.S. (Ed.) The Physics and Chemistry of Inorganic Clathrates; Springer: Dordrecht, Germany, 2014.

62. Beekman, M.; Nolas, G.S. Inorganic clathrate-II materials of group 14: Synthetic routes and physical properties. J. Mater. Chem. 2008, 18, 842851. [CrossRef]

63. Böhme, B.; Hoffmann, S.; Baitinger, M.; Grin, Y. Application of n-Dodecyltrimethylammonium Chloride for the oxidation of intermetallic phases. Z. Naturforsch. 2011, 66b, 230-238. [CrossRef]

64. Carrillo-Cabrera, W.; Cardoso Gil, R.; Somer, M.; Persil, Ö.; von Schnering, H.G. $\mathrm{Na}_{12} \mathrm{Ge}_{17}$ : A Compound with the Zintl Anions $\left[\mathrm{Ge}_{4}\right]^{4-}$ and $\left[\mathrm{Ge}_{9}\right]^{4-}$ : Synthesis, Crystal Structure, and Raman Spectrum. Z. Anorg. Allg. Chem. 2003, 629, 601-608. [CrossRef]

65. Liang, Y.; Böhme, B.; Reibold, M.; Schnelle, W.; Schwarz, U.; Baitinger, M.; Lichte, H.; Grin, Y. Synthesis of the clathrate-I phase $\mathrm{Ba}_{8-x} \mathrm{Si}_{46}$ via redox reactions. Inorg. Chem. 2011, 50, 4523-4528. [CrossRef]

66. Guloy, A.M.; Tang, Z.; Ramlau, R.; Böhme, B.; Baitinger, M.; Grin, Y. Synthesis of the Clathrate-II $\mathrm{K}_{8.6(4)} \mathrm{Ge}_{136}$ by Oxidation of $\mathrm{K}_{4} \mathrm{Ge}_{9}$ in an Ionic Liquid. Eur. J. Inorg. Chem. 2009, 2009, 2455. [CrossRef] 
67. Böhme, B.; Guloy, A.; Tang, Z.; Schnelle, W.; Burkhardt, U.; Baitinger, M.; Grin, Y. Oxidation of $\mathrm{M}_{4} \mathrm{Si}_{4}(\mathrm{M}=$ $\mathrm{Na}, \mathrm{K})$ to Clathrates by $\mathrm{HCl}$ or $\mathrm{H}_{2}$ O. J. Am. Chem. Soc. 2007, 129, 5348. [CrossRef]

68. Neiner, D.; Okamoto, N.L.; Condron, C.L.; Ramasse, Q.M.; Yu, P.; Browning, N.D.; Kauzlarich, S.M. Hydrogen Encapsulation in a Silicon Clathrate Type I Structure: $\mathrm{Na}_{5.5}\left(\mathrm{H}_{2}\right)_{2.15} \mathrm{Si}_{46}$ : Synthesis and Characterization. J. Am. Chem. Soc. 2007, 129, 13857. [CrossRef]

69. Blosser, M.C.; Nolas, G.S. Synthesis of $\mathrm{Na}_{8} \mathrm{Si}_{46}$ and $\mathrm{Na}_{24} \mathrm{Si}_{136}$ by oxidation of $\mathrm{Na}_{4} \mathrm{Si}_{4}$ from ionic liquid decomposition. Mater. Lett. 2013, 99, 161-163. [CrossRef]

70. Kasper, J.S.; Hagenmuller, P.; Pouchard, M.; Cros, C. Clathrate Structure of Silicon $\mathrm{Na}_{8} \mathrm{Si}_{46}$ and $\mathrm{Na}_{x} \mathrm{Si}_{136}(x<$ 11). Science 1965, 150, 1713.

71. Cros, C.; Pouchard, M.; Hagenmuller, P. Sur une nouvelle famille de clathrates minéraux isotypes des hydrates de gaz et de liquides. Interprétation des résultats obtenus. J. Solid State Chem. 1970, 2, 570. [CrossRef]

72. O'Keeffe, M.; Adams, G.B.; Sankey, O.F. Duals of Frank-Kasper structures as C, Si and Ge clathrates: Energetics and structure. Philos. Mag. Lett. 1998, 78, 21. [CrossRef]

73. Böhme, B.; Veremchuk, I.; Lien, N.T.K.; Baitinger, M.; Grin, Y. A new preparation route to intermetallic clathrates. In Proceedings of the 6th European Conference on Thermoelectrics, Paris, France, 2-4 July 2008; p. O-21.

74. Fukuoka, H.; Kiyoto, J.; Yamanaka, S. Superconductivity of Metal Deficient Silicon Clathrate Compounds, $\mathrm{Ba}_{8-x} \mathrm{Si}_{46}(0<x \leq 1.4)$. Inorg. Chem. 2003, 42, 2933-2937.

75. Beekman, M.; Nenghabi, E.N.; Biswas, K.; Myles, C.W.; Baitinger, M.; Grin, Y.; Nolas, G.S. Framework contraction in Na-stuffed $\mathrm{Si}(c F 136)$. Inorg. Chem. 2010, 49, 5338. [CrossRef]

76. Gryko, J.; McMillan, P.F.; Marzke, R.F.; Ramachandran, G.K.; Patton, D.; Deb, S.K.; Sankey, O.F. Low-density framework form of crystalline silicon with a wide optical band gap. Phys. Rev. B 2000, 62, R7707-R7710. [CrossRef]

77. Ammar, A.; Cros, C.; Pouchard, M.; Jaussaud, N.; Bassat, J.-M.; Villeneuve, G.; Duttine, M.; Ménétrier, M.; Reny, E. On the clathrate form of elemental silicon, $\mathrm{Si}_{136}$ : Preparation and characterisation of $\mathrm{Na}_{x} \mathrm{Si}_{136}(x \rightarrow$ 0). Solid State Sci. 2004, 6, 393. [CrossRef]

78. Beekman, M.; Kaduk, J.A.; Huang, Q.; Wong-Ng, W.; Yang, Z.; Wang, D.; Nolas, G.S. Synthesis and crystal structure of $\mathrm{Na}_{1-x} \mathrm{Ge}_{3+z}$ : A novel zeolite-like framework phase in the Na-Ge system. Chem. Commun. 2007, 2007, 837. [CrossRef]

79. Stefanoski, S.; Finkelstein, G.J.; Ward, M.D.; Zeng, T.; Wei, K.; Bullock, E.S.; Beavers, C.M.; Liu, H.; Nolas, G.S.; Strobel, T.A. Zintl ions within framework channels: The complex structure and low-temperature transport properties of $\mathrm{Na}_{4} \mathrm{Ge}_{13}$. Inorg. Chem. 2018, 57, 2002-2012. [CrossRef]

80. Baranowski, L.L.; Krishna, L.; Martinez, A.D.; Raharjo, T.; Stevanović, V.; Tamboli, A.C.; Toberer, E.S. Synthesis and optical band gaps of alloyed Si-Ge type II clathrates. J. Mater. Chem. C 2014, 2, 3231-3237. [CrossRef]

81. Stefanoski, S.; Beekman, M.; Wong-Ng, W.; Zavalij, P.; Nolas, G.S. Simple approach for selective crystal growth of intermetallic clathrates. Chem. Mater. 2011, 23, 1491-1495. [CrossRef]

82. Krishna, L.; Baranowski, L.L.; Martinez, A.D.; Koh, C.A.; Taylor, P.C.; Tamboli, A.C.; Toberer, E.C. Efficient route to phase selective synthesis of type II silicon clathrates with low sodium occupancy. CrystEngComm 2014, 16, 3940-3949. [CrossRef]

83. Morito, H.; Shimoda, M.; Yamane, H.; Fujiwara, K. Crystal Growth Conditions of Types I and II Na-Si Clathrates by Evaporation of $\mathrm{Na}$ from a Na-Si-Sn Solution. Cryst. Growth Des. 2018, 18, 351-355. [CrossRef]

84. Dong, Y.; Nolas, G.S. Crystal Growth through Field-Assisted Electrochemical Redox and Ion-Exchange Reactions: A Case Study of $\mathrm{K}_{4.2} \mathrm{Na}_{3.8} \mathrm{Si}_{46}$ Clathrate-I. Cryst. Growth Des. 2015, 15, 4731-4734. [CrossRef]

85. Wei, K.; Dong, Y.; Nolas, G.S. Precursor routes to quaternary intermetallics: Synthesis, crystal structure, and physical properties of clathrate-II $\mathrm{Cs}_{8} \mathrm{Na}_{16} \mathrm{Al}_{24} \mathrm{Si}_{112}$. J. Solid State Chem. 2016, 237, 81-85. [CrossRef]

86. Hutchins, P.T.; Leynaud, O.; O’Dell, L.A.; Smith, M.E.; Barnes, P.; McMillan, P.F. Time-Resolved in Situ Synchrotron X-ray Diffraction Studies of Type 1 Silicon Clathrate Formation. Chem. Mater. 2011, 23, 5160. [CrossRef]

87. Egami, T.; Billinge, S.J.L. Underneath the Bragg Peaks: Structural Analysis of Complex Materials; Pergamon: Amsterdam, The Netherlands, 2003. 
88. Slingsby, J.G.; Rorrer, N.A.; Krishna, L.; Toberer, E.S.; Koh, C.A.; Maupin, C.M. Dynamic free energy surfaces for sodium diffusion in type II silicon clathrates. PhysChemPhys 2015, 2015, 1-8. [CrossRef]

89. Reijers, H.T.J.; Saboungi, M.-L.; Price, D.L.; Richardson, J.W., Jr.; Volin, K.J.; van der Lugt, W. Structural properties of liquid alkali-metal —Lead alloys: $\mathrm{NaPb}, \mathrm{KPb}, \mathrm{RbPb}$, and CsPb. Phys. Rev. B 1989, 40, 6018. [CrossRef]

90. Saboungl, M.-L.; Fortner, J.; Howells, W.S.; Price, D.L. Dynamic enhancement of cation migration in a Zintl alloy by polyanion rotation. Nature 1993, 365, 237. [CrossRef]

91. Stoddard, R.D.; Conradi, M.S.; McDowell, A.F.; Saboungi, M.-L.; Price, D.L. Atomic motions in an unusual molecular semiconductor: NaSn. Phys. Rev. B 1995, 52, 13998. [CrossRef]

92. Kiefer, F.; Hlukhyy, V.; Karttunen, A.J.; Fässler, T.F.; Gold, C.; Scheidt, E.-W.; Scherer, W.; Nylén, J.; Häussermann, U. Synthesis, structure, and electronic properties of $4 \mathrm{H}$-germanium. J. Mater. Chem. 2010, 20, 1780-1786. [CrossRef]

93. Schwarz, U.; Wosylus, A.; Böhme, B.; Baitinger, M.; Hanfland, M.; Grin, Y. A 3D network of four-bonded Germanium: A link between open and dense. Angew. Chem. Int. Ed. 2008, 47, 6790-6793. [CrossRef]

94. Krishna, L.; Chai, P.; Koh, C.A.; Toberer, E.S.; Nolas, G.S. Synthesis and structural properties of type I potassium SiGe alloy clathrates. Mater. Lett. 2015, 149, 123-125.

95. Moriguchi, K.; Munetoh, S.; Shintani, A. First-principles study of $\mathrm{Si}_{34-x} \mathrm{Ge}_{\mathrm{x}}$ clathrates: Direct wide-gap semiconductors in Si-Ge alloys. Phys. Rev. B 2000, 62, 7138. [CrossRef]

96. Scott, B.J.; Wirnsberger, G.; Stucky, G.D. Mesoporous and Mesostructured Materials for Optical Applications. Chem. Mater. 2001, 13, 3140-3150. [CrossRef]

97. Sun, D.; Riley, A.E.; Cadby, A.J.; Richman, E.K.; Korlann, S.D.; Tolbert, S.H. Hexagonal nanoporous germanium through surfactant-driven self-assembly of Zintl clusters. Nature 2006, 441, 1126-1130. [CrossRef]

98. Armatas, G.S.; Kanatzidis, M.G. Mesostructured germanium with cubic pore symmetry. Nature 2006, 441, 1122-1125. [CrossRef]

99. Armatas, G.S.; Kanatzidis, M.G. Hexagonal mesoporous germanium. Science 2006, 313, 817-820. [CrossRef]

100. Bentlohner, M.M.; Waibel, M.; Zeller, P.; Sarkar, K.; Müller-Buschbaum, P.; Fattakhova-Rohlfing, D.; Fässler, T.F. Zintl Clusters as wet-chemical precursors for Germanium nanomorphologies with tunable Composition. Angew. Chem. Int. Ed. 2016, 55, 2441-2445. [CrossRef]

101. Geier, S.; Jung, R.; Peters, K.; Gasteiger, H.A.; Fattakhova-Rohlfing, D.; Fässler, T.F. A wet-chemical route for macroporous inverse opal Ge anodes for lithium ion batteries with high capacity retention. Sustain. Energy Fuels 2018, 2, 85-90. [CrossRef]

102. McVey, B.F.P.; Prabakar, S.; Gooding, J.J.; Tilley, R.D. Solution Synthesis, Surface Passivation, Optical Properties, Biomedical Applications, and Cytotoxicity of Silicon and Germanium Nanocrystals. ChemPlusChem 2017, 82, 60-73. [CrossRef]

103. Peng, F.; Su, Y.; Zhong, Y.; Fan, C.; Lee, S.-T.; He, Y. Silicon Nanomaterials Platform for Bioimaging, Biosensing, and Cancer Therapy. Acc. Chem. Res. 2014, 47, 612-623. [CrossRef]

104. Vaughn, D.D., 2nd; Schaak, R.E. Synthesis, properties and applications of colloidal germanium and germanium-based nanomaterials. Chem. Soc. Rev. 2013, 42, 2861-2879. [CrossRef]

105. Veinot, J.G.C. Synthesis, surface functionalization, and properties of freestanding silicon nanocrystals. Chem. Commun. 2006, 2006, 4160-4168. [CrossRef]

106. Jiang, S.; Arguilla, M.Q.; Cultrara, N.D.; Goldberger, J.E. Covalently-controlled properties by design in group IV graphane analogues. Acc. Chem. Res. 2015, 48, 144-151. [CrossRef]

107. Parkin, I.P. Solid state metathesis reaction for metal borides, silicides, pnictides and chalcogenides: Ionic or elemental pathways. Chem. Soc. Rev. 1996, 1996, 199-207. [CrossRef]

108. Mayeri, D.; Phillips, B.L.; Augustine, M.P.; Kauzlarich, S.M. NMR study of the synthesis of alkyl-terminated silicon nanoparticles from the reaction of $\mathrm{SiCl}_{4}$ with the Zintl salt, NaSi. Chem. Mater. 2001, 13, 765-770. [CrossRef]

109. Bley, R.A.; Kauzlarich, S.M. A low-temperature solution phase route for the synthesis of silicon nanoclusters. J. Am. Chem. Soc. 1996, 118, 12461-12462. [CrossRef]

110. Yang, C.S.; Bley, R.A.; Kauzlarich, S.M.; Lee, H.W.H.; Delgado, G.R. Synthesis of alkyl-terminated silicon nanoclusters by a solution route. J. Am. Chem. Soc. 1999, 121, 5191-5195. [CrossRef]

111. Taylor, B.R.; Kauzlarich, S.M.; Lee, H.W.H.; Delgado, G.R. Solution Synthesis of Germanium Nanocrystals Demonstrating Quantum Confinement. Chem. Mater. 1998, 10, 22-24. [CrossRef] 
112. Taylor, B.R.; Kauzlarich, S.M.; Delgado, G.R.; Lee, H.W.H. Solution Synthesis and Characterization of Quantum Confined Ge Nanoparticles. Chem. Mater. 1999, 11, 2493-2500. [CrossRef]

113. Yang, C.-S.; Kauzlarich, S.M.; Wang, Y.C. Synthesis and Characterization of Germanium/Si-alkyl and Germanium/Silica Core-Shell Quantum Dots. Chem. Mater. 1999, 11, 3666-3670. [CrossRef]

114. Yang, C.S.; Liu, Q.; Kauzlarich, S.M.; Phillips, B. Synthesis and characterization of Sn/R, Sn/Si-R, and $\mathrm{Sn} / \mathrm{SiO}_{2}$ core/shell nanoparticles. Chem. Mater. 2000, 12, 983-988. [CrossRef]

115. Bux, S.K.; Rodriguez, M.; Yeung, M.T.; Yang, C.; Makhluf, A.; Blair, R.G.; Fleurial, J.-P.; Kaner, R.B. Rapid Solid-State Synthesis of Nanostructured Silicon. Chem. Mater. 2010, 22, 2534-2540. [CrossRef]

116. Pettigrew, K.A.; Liu, Q.; Power, P.P.; Kauzlarich, S.M. Solution Synthesis of Alkyl- and Alkyl/Alkoxy-Capped Silicon Nanoparticles via Oxidation of $\mathrm{Mg}_{2} \mathrm{Si}$. Chem. Mater. 2003, 15, 4005-4011. [CrossRef]

117. Annou, K.; Pelosi, M.; Gershinsky, G.; Favier, F.; Cuminal, Y.; Tillard, M.; Zitoun, D. Oxidation pathways towards $\mathrm{Si}$ amorphous layers or nanocrystalline powders as Li-ion batteries anodes. Mater. Renew. Sustain. Energy 2014, 3, 32. [CrossRef]

118. Meyer, G. The Oxidation of Metals with Liebig Acids. Z. Anorg. Allg. Chem. 2007, 634, 201-222. [CrossRef]

119. McMillan, P.F.; Gryko, J.; Bull, C.; Arledge, R.; Kenyon, A.J.; Cressey, B.A. Amorphous and nanocrystalline luminescent $\mathrm{Si}$ and Ge obtained via a solid-state chemical metathesis synthesis route. J. Solid State Chem. 2005, 178, 937-949. [CrossRef]

120. Neiner, D.; Chiu, H.W.; Kauzlarich, S.M. Low-Temperature Solution Route to Macroscopic Amounts of Hydrogen Terminated Silicon Nanoparticles. J. Am. Chem. Soc. 2006, 128, 11016-11017. [CrossRef]

121. Ma, X.; Wu, F.; Kauzlarich, S.M. Alkyl-terminated crystalline Ge nanoparticles prepared from NaGe: Synthesis, functionalization and optical properties. J. Solid State Chem. 2008, 181, 1628-1633. [CrossRef]

122. Zhang, X.; Neiner, D.; Wang, S.; Louie, A.; Kauzlarich, S. A new solution route to hydrogen terminated silicon nanoparticles: Synthesis, functionlization and water stability. Nanotechnology 2007, 18, 095601. [CrossRef]

123. Wang, J.L.; Ganguly, S.; Sen, S.; Browning, N.D.; Kauzlarich, S.M. Synthesis and characterization of P-doped amorphous and nanocrystalline Si. Polyhedron 2013, 58, 156-161. [CrossRef]

124. Atkins, T.M.; Thibert, A.; Larsen, D.S.; Dey, S.; Browning, N.D.; Kauzlarich, S.M. Femtosecond Ligand/Core Dynamics of Microwave-Assisted Synthesized Silicon Quantum Dots in Aqueous Solution. J. Am. Chem. Soc. 2011, 133, 20664-20667. [CrossRef]

125. Singh, M.P.; Atkins, T.M.; Muthuswamy, E.; Kamali, S.; Tu, C.; Louie, A.Y.; Kauzlarich, S.M. Development of Iron Doped Silicon Nanoparticles as Bimodal Imaging Agents. ACS Nano 2012, 6, 5596-5604. [CrossRef]

126. Atkins, T.M.; Walton, J.H.; Singh, M.P.; Ganguly, S.; Janka, O.; Louie, A.Y.; Kauzlarich, S.M. EPR and Structural Characterization of Water-Soluble Mn(2+)-Doped Si Nanoparticles. J. Phys. Chem. C 2017, 121, 1948-1956. [CrossRef]

127. Atkins, T.M.; Louie, A.Y.; Kauzlarich, S.M. An efficient microwave-assisted synthesis method for the production of water-soluble amine-terminated Si nanoparticles. Nanotechnology 2012, 23, 294006. [CrossRef]

128. Tu, C.; Ma, X.; Pantazis, P.; Kauzlarich, S.M.; Louie, A.Y. Paramagnetic, Silicon Quantum Dots for Magnetic Resonance and Two-Photon Imaging of Macrophages. J. Am. Chem. Soc. 2010, 132, 2016-2023. [CrossRef]

129. Zhang, X.; Brynda, M.; Britt, R.D.; Carroll, E.C.; Larsen, D.S.; Louie, A.Y.; Kauzlarich, S.M. Synthesis and characterization of manganese-doped silicon nanoparticles: Bifunctional paramagnetic-optical nanomaterial. J. Am. Chem. Soc. 2007, 129, 10668. [CrossRef]

130. Bhattacharjee, S.; Rietjens, I.M.; Singh, M.P.; Atkins, T.M.; Purkait, T.K.; Xu, Z.; Regli, S.; Shukaliak, A.; Clark, R.J.; Mitchell, B.S.; et al. Cytotoxicity of surface-functionalized silicon and germanium nanoparticles: The dominant role of surface charges. Nanoscale 2013, 5, 4870-4883. [CrossRef]

131. Nolan, B.M.; Henneberger, T.; Waibel, M.; Fässler, T.F.; Kauzlarich, S.M. Silicon nanoparticles by the oxidation of $\left[\mathrm{Si}_{4}\right]^{4-}$ - and $\left[\mathrm{Si}_{9}\right]^{4-}$-containing Zintl phases and their corresponding yield. Inorg. Chem. 2015, 54, 396-401. [CrossRef]

132. Weiss, A.; Beil, G.; Meyer, H. The Topochemical Reaction of $\mathrm{CaSi}_{2}$ to a Two-Dimensional Subsiliceous Acid $\mathrm{Si}_{6} \mathrm{H}_{3}(\mathrm{OH})_{3}$ (= Kautskys' Siloxene). Z. Naturforsch. 1979, 34b, 25-30. [CrossRef]

133. Hönle, U.D.-W.W.; Molassioti-Dohms, A.; Finkbeiner, S.; Weber, J. Structure and optical properties of the planar silicon compounds polysilane and Wöhler siloxene. Phys. Rev. B 1997, 56, 13132.

134. Fuchs, H.D.; Stutzmann, M.; Brandt, M.S.; Rosenbauer, M.; Weber, J.; Breitschwerdt, A.; Deák, P.; Cardona, M. Porous silicon and siloxene: Vibrational and structural properties. Phys. Rev. B 1993, 48, 8172-8189. [CrossRef] 
135. Vogg, G.; Brandt, M.S.; Stutzmann, M. Polygermyne-A Prototype System for Layered Germanium Polymers. Adv. Mater. 2000, 12, 1278-1281. [CrossRef]

136. Bianco, E.; Butler, S.; Jiang, S.; Restrepo, O.D.; Windl, W.; Goldberger, J.E. Stability and Exfoliation of Germanane: A Germanium Graphane Analogue. ACS Nano 2013, 7, 4414-4421. [CrossRef]

137. Chandrasekharan, N.; Sevov, S.C. Anodic electrodeposition of Germanium films from ethylenediamine solutions of deltahedral Ge ${ }^{4-}$ Zintl ions. J. Electrochem. Soc. 2010, 157, C140-C145. [CrossRef]

138. Scherf, L.M.; Hattendorff, J.; Buchberger, I.; Geier, S.; Gasteiger, H.A.; Fässler, T.F. Electrochemical synthesis of the allotrope allo-Ge and investigations on its use as anode material. J. Mater. Chem. A 2017, 5, 11179-11187. [CrossRef]

139. Beekman, M.; Baitinger, M.; Borrmann, H.; Schnelle, W.; Meier, K.; Nolas, G.S.; Grin, Y. Preparation and Crystal Growth of $\mathrm{Na}_{24} \mathrm{Si}_{136}$. J. Am. Chem. Soc. 2009, 131, 9642. [CrossRef]

140. Veremchuk, I.; Beekman, M.; Antonyshyn, I.; Baitinger, M.; Nolas, G.S.; Grin, Y. Binary Alkali-Metal Silicon Clathrates by Spark Plasma Sintering: Preparation and Characterization. Materials 2016, 9, 593. [CrossRef]

(C) 2019 by the authors. Licensee MDPI, Basel, Switzerland. This article is an open access article distributed under the terms and conditions of the Creative Commons Attribution (CC BY) license (http:/ / creativecommons.org/licenses/by/4.0/). 